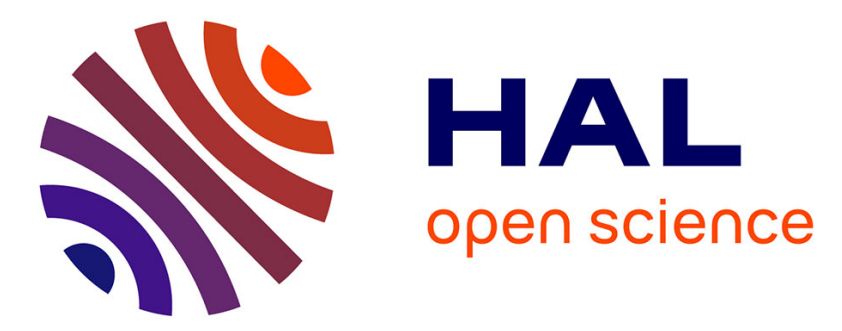

\title{
Comparative study of pyrolytic decomposition of polymers alone or in EVA/PS, EVA/PVC and EVA/cellulose mixtures
}

Yannick Soudais, Ludivine Moga, Jaroslav Blazek, Florent Lemort

\section{To cite this version:}

Yannick Soudais, Ludivine Moga, Jaroslav Blazek, Florent Lemort. Comparative study of pyrolytic decomposition of polymers alone or in EVA/PS, EVA/PVC and EVA/cellulose mixtures. Journal of Analytical and Applied Pyrolysis, 2007, 80 (1), pp.36-52. 10.1016/j.jaap.2006.12.033 . hal-01713902

\section{HAL Id: hal-01713902 \\ https://hal.science/hal-01713902}

Submitted on 13 Dec 2018

HAL is a multi-disciplinary open access archive for the deposit and dissemination of scientific research documents, whether they are published or not. The documents may come from teaching and research institutions in France or abroad, or from public or private research centers.
L'archive ouverte pluridisciplinaire HAL, est destinée au dépôt et à la diffusion de documents scientifiques de niveau recherche, publiés ou non, émanant des établissements d'enseignement et de recherche français ou étrangers, des laboratoires publics ou privés. 


\title{
Comparative study of pyrolytic decomposition of polymers alone or in EVA/PS, EVA/PVC and EVA/cellulose mixtures
}

\author{
Yannick Soudais ${ }^{\mathrm{a}, *}$, Ludivine Moga ${ }^{\mathrm{a}}$, Jaroslav Blazek ${ }^{\mathrm{a}}$, Florent Lemort ${ }^{\mathrm{b}}$ \\ ${ }^{a}$ UMR CNRS 2392, Laboratoire de Génie des Procédés des Solides Divisés, École des Mines d'Albi-Carmaux, Campus Jarlard, 81013 Albi, France \\ ${ }^{\mathrm{b}}$ CEA Valrhô-Marcoule, Laboratoire de Procédés Innovants de Conditionnement (LPIC) BP 17171, 30207 Bagnols-sur-Cèze Cedex, France
}

\begin{abstract}
The behavior of mixtures of EVA-PS, EVA-PVC and EVA-cellulose in various proportions were investigated under pyrolysis. A kinetic model with an independent pathway is proposed for the weight loss and compared with the experimental and theoretical results obtained in a previous study with individual polymers. The kinetic parameters were determined and online IR spectrometric analysis used to follow the evolution of the gaseous pyrolysis products versus the temperature. The result shows good agreement for the EVA-PS mixture and confirms the hypothesis of an independent pathway. However, in the case of EVA-PVC and EVA-cellulose mixtures, the polymers affect one other in the pyrolysis reaction.
\end{abstract}

Keywords: EVA-cellulose; EVA-PVC; EVA-PS

\section{Introduction}

The thermal degradation of widely used polymers or biopolymers (EVA, PE, PP, PS, PVC, PET, cellulose, lignin, etc.) has been described in the literature. The pyrolysis of these polymers has been studied in detail and many published articles describe the mechanism and rate of decomposition, but less information is available on polymer mixtures. As these materials are found in mixtures in MSW, it is of interest to determine how they interact during a thermal degradation process. Waste pyrolysis could be a clean alternative to incineration because it combines material recovery with energy production and minimizes the ultimate residues. In Europe there is currently rising interest in biomethanization, pyrolysis and vitrification processes as alternatives to incineration. Murata and Makino [1] studied the pyrolysis of mixtures of PE, PS, PP and noted that these polymers interact only slightly. Knuemann and Bockhorn [2] found no significant influence of PVC on PE, PS and PP, except with PA. We chose to investigate the degradation under pyrolysis conditions of binary mixtures of polymers in which one of the components is EVA. This

\footnotetext{
* Corresponding author.

E-mail address: Yannick.soudais@enstimac.fr (Y. Soudais).
}

copolymer (ethylene vinyl acetate) with different percentages of vinyl acetate (VA) is very extensively used, especially in the production of cables, piping, adhesive tape, etc. Ethylene vinyl acetate copolymers represent the largest volume segment of the ethylene copolymer market. Their properties depend on the VA content: products ranging from 2 to $40 \%$ VA are marketed for different purposes. The properties of mixtures were compared with those of pure materials based on thermal analysis and online FTIR analysis findings. Significant interaction was confirmed in the case of EVA-PVC mixtures.

An extensive bibliography [3-14] is available on the degradation of EVA and the estimated kinetic parameters of the process. Basically, the thermal degradation of EVA copolymers is a two-step process. The first step, occurring in the temperature range from 300 to $400{ }^{\circ} \mathrm{C}$, consists in the elimination of one acetic acid molecule, leading to the formation of an ethylene structure on the rest of the carbon chain instead of the previous carbonyl function group. For this reaction, the radical mechanism and ionic elimination have been proposed [15]. poly[ethylene-co-(acetylene)] (PEA), formed in the first stage, begins to decompose into smaller chains by the mechanism of the random splitting of the carbon skeleton. This second stage occurs around $425{ }^{\circ} \mathrm{C}$ [16] or $470{ }^{\circ} \mathrm{C}$ [17]. The decomposition of the acetoxy groups is favored by the tendency to form a six ring transition state (via a 
hydrogen bond with active methylene groups). The activated complex decomposes thermally, eliminating the acetic acid [18].

The thermal degradation of PS is a radical chain mechanism, where initiation, propagation and termination reactions are the relevant reaction classes. Two types of initiation reactions can be identified [3]. It has been shown that styrene is the primary PS decomposition product [21]. Various kinetic models have been proposed in the literature. Marcilla and Beltran [19] analyzed two types of models, and concluded that the best models are those that involve the formation of an intermediate species, with gases generated in two stages. They also chose this model for the degradation of EVA.

The thermal degradation of PVC has been the subject of numerous investigations [34,35] and various kinetic models have been proposed in the literature [22-28] to quantitatively describe the chemical reactions that take place during PVC pyrolysis. It is generally considered a two- or three-step process (depending on the authors) in which the first step is the loss of one $\mathrm{HCl}$ molecule by a free radical mechanism beginning at about $200{ }^{\circ} \mathrm{C}$ and resulting in the formation of polyene in competition with the formation of a cross-linked structure involving different chain radicals. The second and third steps are parallel reactions, occurring in the range of $350-520^{\circ} \mathrm{C}$. Cracking of some carbon-carbon bonds of the previous polyene structures occurs where monocyclic and polycyclic aromatics compounds like benzene, toluene and naphthalene derivatives obtained by cyclization of the conjugated olefin intermediate structures are formed rather than aliphatic structures.

Cellulose is the most widely studied substance in the field of wood and biomass. The kinetics of cellulose pyrolysis have been extensively investigated by numerous researchers and many kinetic schemes have been proposed [29-32]. Despite the research effort, however, the various mechanisms are not fully known. The degradation of cellulose consists of a complex set of reactions. Font et al. showed that the modified Kilzer-Broido (KBM) model of kinetic thermal decomposition of cellulose yields the best results, and that with all models that take the activation of cellulose into account (with the formation of anhydrocellulose in the first step) the agreement between experimental and calculated values increases.

This paper discusses a study of the behavior under pyrolysis of EVA-PS, EVA-PVC and EVA-cellulose mixtures in various proportions. Kinetic models for the weight loss were proposed and compared with the experimental results; the kinetic parameters were determined and IR spectrometric analysis used to follow the online evolution of the gaseous products of pyrolysis as a function of temperature.

In a previous paper [33], the behavior of each single polymer was studied under the influence of heat, with different heating rates. The results given by the models proposed for the progressive weight loss were compared with the experimental findings. The kinetic parameters were determined and compared with the available published data. Analysis of online FTIR spectra confirmed the initial loss of acetic acid for EVA and of the $\mathrm{HCl}$ molecule for PVC. In the case of cellulose the result is more complicated, but evolved gas analysis shows that degradation first occurs with the formation of $\mathrm{CO}, \mathrm{CO}_{2}$ and water vapor, follow by a second step in which alkane, alkene, aldehyde and ketone gases are formed.

In the case of mixtures, the proposed kinetic models of weight loss were based on the assumption of an independent pathway for each polymer during pyrolysis. The corresponding evolved gases were analyzed by online FTIR and the main products were identified. The results were compared with those for individual polymers and show that in the case of EVA-PVC and EVA-cellulose mixtures the polymers interact during pyrolysis.

\section{Experimental}

\subsection{Materials}

All samples in the present study (EVA, PS, PVC, cellulose) were pure polymers from Aldrich Chemical Company. EVA with $25 \%$ VA content was used for the mixture studies at ratios of $1: 3,1: 1$ and $3: 1$.

\subsection{Thermogravimetric and online FTIR analysis}

Samples weighing between 20 and $40 \mathrm{mg}$ were placed in the platinum crucible of the thermobalance. Heating rates ranging from 5 to $30{ }^{\circ} \mathrm{C} \mathrm{min}^{-1}$ were applied, and duplicate runs were carried out at all heating rates. Pyrolysis was carried out in $\mathrm{N}_{2}$ atmosphere, with the gas flow maintained at $27 \mathrm{~cm}^{3} \mathrm{~min}^{-1}$. A Setaram model TGA 92-16 thermobalance was connected to the FTIR spectrophotometer by means of a heated line to allow continuous recordings of the IR spectra corresponding to the evolved gases. The spectrophotometer was a Perkin-Elmer System 2000 equipped with a gas cell and a DTGS detector with a resolution of $8 \mathrm{~cm}^{-1}$. The heated line and gas-cell were temperature-regulated and maintained at $250{ }^{\circ} \mathrm{C}$ to prevent unwanted condensation and guarantee the most quantitative transfer possible of gaseous decomposition products and high detection sensitivity. The evolved gases were continuously recorded with TimeBase ${ }^{\mathbb{R}}$ and the spectrum analysis was performed with the KnowItAll ${ }^{\circledR}$ analytical system.

A precise, rigorous experimental protocol was followed to add the polymers to the crucible. The pure compounds were always added in identical order for all experiments.

As mentioned above, before investigating mixed polymers we studied the pure polymers and compared our findings with published data. The results of this study are discussed in a previous paper (submitted for publication). We analyzed the experimental curves for the pure polymers to determine the temperatures of the DTG peaks (maximum degradation rate temperatures). For each curve we noted the following data:

- DTG peak temperatures;

- DTG values corresponding to each peak;

- weight loss percentages.

We proceeded in the same way for the mixed polymer curves. 
For all the TGA analysis curves the initial and final decomposition temperatures were variable, and the temperature increased with the heating rate, as expected.

We assumed independent degradation of each constituent in the mixtures. The models were then programmed in MATLAB for each mixture and compared with the experimental results. We identified which polymer was degraded for each weight loss and verified the consistency of the results with the analyses performed on pure polymers. Generally we observed that the weight loss percentage depended to some extent on the heating rate, but also on the polymer fraction degraded in the mixture. The degradation temperatures increased with the heating rate. The DTG values depended both on the heating rate and on the degraded polymer fraction.

\section{Results and discussion}

\subsection{Thermal analysis}

For each mixture EVA/PS and EVA/PVC, the test heating rates were 5,10 , and $20{ }^{\circ} \mathrm{C} \mathrm{min}{ }^{-1}$; a total of nine experiments were therefore carried out.

\subsubsection{EVA/PS mixture}

Analyzing the experimental curves for the EVA/PS mixture revealed three weight losses corresponding in chronological order to the following degradation stages:

- first weight loss: EVA at about $340{ }^{\circ} \mathrm{C}$;

- second weight loss: PS at about $420{ }^{\circ} \mathrm{C}$;

- third weight loss: EVA at about $470{ }^{\circ} \mathrm{C}$.

Table 1 indicates the characteristic values measured during experiments at different heating rates, i.e. the measured DTG peak temperatures, DTG percentages, and weight loss values.

3.1.1.1. Experimental results for EVA and PS alone. Tables 2 and 3 show the temperatures of the DTG peaks observed during pyrolysis of the pure polymers. These temperatures constitute the reference values for identifying the compounds that degrade during pyrolysis of the mixed polymers. As before, the tables
Table 2

Weight losses, DTG values, and DTG peak temperatures for pure EVA

\begin{tabular}{|c|c|c|c|c|c|c|}
\hline \multirow{2}{*}{$\begin{array}{l}\text { Heating } \\
\text { rate } \\
\left({ }^{\circ} \mathrm{C} \mathrm{min}{ }^{-1}\right)\end{array}$} & \multicolumn{2}{|c|}{$\begin{array}{l}\text { DTG peak } \\
\text { temperature }\left({ }^{\circ} \mathrm{C}\right)\end{array}$} & \multicolumn{2}{|c|}{$\begin{array}{l}\text { DTG value } \\
\left(\% \min ^{-1}\right)\end{array}$} & \multicolumn{2}{|c|}{$\begin{array}{l}\text { Weight } \\
\text { loss }(\%)\end{array}$} \\
\hline & $\begin{array}{l}\text { First } \\
\text { loss }\end{array}$ & $\begin{array}{l}\text { Second } \\
\text { loss }\end{array}$ & $\begin{array}{l}\text { First } \\
\text { loss }\end{array}$ & $\begin{array}{l}\text { Second } \\
\text { loss }\end{array}$ & $\begin{array}{l}\text { First } \\
\text { loss }\end{array}$ & $\begin{array}{l}\text { Second } \\
\text { loss }\end{array}$ \\
\hline 5 & 345 & 461 & -1.9 & -10.5 & 22.4 & 77.6 \\
\hline 10 & 355 & 474 & -3.6 & -20.5 & 25.8 & 67.2 \\
\hline 20 & 367 & 483 & -6.8 & -29.8 & 27.2 & 72.8 \\
\hline 30 & 375 & 489 & -8.75 & -37.25 & 28.4 & 91.6 \\
\hline
\end{tabular}

indicate the DTG peak temperatures, the DTG percentage, and the weight losses versus the heating rates for EVA alone and for PS alone. Two weight losses were observed for EVA and a single weight loss for PS.

3.1.1.2. EVA/PS mixture: analysis of experimental results. Table 1 indicates three weight losses. The measured weight losses are expressed as a percentage of the initial weight. When the sum is not equal to 100 , this implies that a solid residue remained in the crucible after pyrolysis.

Comparing the peak temperatures for the mixtures with the ones for the pure compounds provides an initial indication of the degradation chronology of each polymer in the mixture. This method assumes that each of the compounds is degraded independently.

The first degradation, with a maximum rate at about 330 $365^{\circ} \mathrm{C}$, can be identified with the first weight loss for pure EVA, which occurs in the same range $\left(340-365^{\circ} \mathrm{C}\right)$. The second stage of degradation occurs between 405 and $435{ }^{\circ} \mathrm{C}$, which corresponds to the degradation temperature of polystyrene alone: $410-440{ }^{\circ} \mathrm{C}$. The third degradation, between 455 and $480{ }^{\circ} \mathrm{C}$, corresponds to the second weight loss for pure EVA, which also occurs between 455 and $480{ }^{\circ} \mathrm{C}$. The degradation temperatures generally increase with the heating rate.

This was confirmed by analysis of the DTG values. The DTG value of the experimental weight loss ( $i$ ) was compared with a theoretical value calculated with the following equation:

$X a(T, i) \times \mathrm{DTG} a(i)$

Table 1

Graphical readout of experimental curves for EVA/PS mixture

\begin{tabular}{|c|c|c|c|c|c|c|c|c|c|c|}
\hline \multirow[t]{2}{*}{ Mixture } & \multirow{2}{*}{$\begin{array}{l}\text { Heating rate } \\
\left({ }^{\circ} \mathrm{C} \min ^{-1}\right)\end{array}$} & \multicolumn{3}{|c|}{ DTG peak temperature $\left({ }^{\circ} \mathrm{C}\right)$} & \multicolumn{3}{|c|}{ DTG value $\left(\% \min ^{-1}\right)$} & \multicolumn{3}{|c|}{ Weight loss (\%) } \\
\hline & & $\begin{array}{l}\text { First } \\
\text { loss }\end{array}$ & $\begin{array}{l}\text { Second } \\
\text { loss }\end{array}$ & $\begin{array}{l}\text { Third } \\
\text { loss }\end{array}$ & $\begin{array}{l}\text { First } \\
\text { loss }\end{array}$ & $\begin{array}{l}\text { Second } \\
\text { loss }\end{array}$ & $\begin{array}{l}\text { Third } \\
\text { loss }\end{array}$ & $\begin{array}{l}\text { First } \\
\text { loss }\end{array}$ & $\begin{array}{l}\text { Second } \\
\text { loss }\end{array}$ & $\begin{array}{l}\text { Third } \\
\text { loss }\end{array}$ \\
\hline \multirow[t]{3}{*}{$25 \%$ EVA } & 5 & 329 & 408 & 454 & -0.7 & -11.4 & -2.6 & 10.2 & 70.6 & 19.2 \\
\hline & 10 & 343 & 420 & 463 & -1.6 & -20.5 & -5.4 & 8.5 & 67.2 & 21.2 \\
\hline & 20 & 359 & 430 & 473 & -2.6 & -37.4 & -12.1 & 9.2 & 65.4 & 22.3 \\
\hline \multirow[t]{3}{*}{$50 \%$ EVA } & 5 & 335 & 408 & 458 & -1.1 & -7.8 & -5.3 & 11.0 & 54.1 & 34.9 \\
\hline & 10 & 350 & 422 & 471 & -2.5 & -15.7 & -11.1 & 10.0 & 47.3 & 42.7 \\
\hline & 20 & 355 & 424 & 477 & -4.6 & -26.8 & -24.6 & 10.0 & 48.5 & 39.4 \\
\hline \multirow[t]{3}{*}{$75 \%$ EVA } & 5 & 338 & 410 & 463 & -1.6 & -4.6 & -9.5 & 14.1 & 40.8 & 45.1 \\
\hline & 10 & 353 & 426 & 467 & -3.4 & -8.9 & -14.8 & 13.9 & 27.3 & 55.8 \\
\hline & 20 & 366 & 433 & 476 & -6.5 & -18.3 & -30.2 & 13.9 & 38.5 & 45.2 \\
\hline
\end{tabular}


Table 3

Results (temperature and DTG) for pyrolysis of PS alone

\begin{tabular}{lll}
\hline $\begin{array}{l}\text { Heating rate } \\
\left({ }^{\circ} \mathrm{C} \mathrm{min}^{-1}\right)\end{array}$ & $\begin{array}{l}\text { DTG peak } \\
\text { temperature }\left({ }^{\circ} \mathrm{C}\right)\end{array}$ & $\begin{array}{l}\text { DTG value } \\
\left(\% \mathrm{~min}^{-1}\right)\end{array}$ \\
\hline 5 & 413 & -14.7 \\
10 & 426 & -24.6 \\
20 & 440 & -42.9 \\
\hline
\end{tabular}

Table 4

DTG values for degradation of the EVA/PS mixture at $5{ }^{\circ} \mathrm{C} \mathrm{min}{ }^{-1}$

\begin{tabular}{llll}
\hline Weight loss & Observation & $\begin{array}{l}\text { Experimental } \\
\text { value }\left(\% \mathrm{~min}^{-1}\right)\end{array}$ & $\begin{array}{l}\text { Theoretical } \\
\text { value }\left(\% \mathrm{~min}^{-1}\right)\end{array}$ \\
\hline First & EVA degradation & -0.7 & -0.55 \\
Second & PS degradation & -11.4 & -11 \\
Third & EVA degradation & -2.6 & -2.4 \\
\hline
\end{tabular}

where:

- $X a(T, i)$ is the fraction of $a$ that degrades during weight loss $i$;

- DTG $a(i)$ is the DTG value of weight loss $i$ at the same heating rate for the pure polymer.

Table 4 shows the results obtained for the 1:3 EVA/PS mixture at $5{ }^{\circ} \mathrm{C} \mathrm{min}^{-1}$.

All the values are of the same order of magnitude; this is consistent with the hypothesis concerning the chronological order of degradation. Another test involves the DTG value of a given weight loss with the polymer fraction: this value varies with the proportion of the polymer that degrades during the weight loss. The DTG value generally increases with the heating rate. The degradation rate thus increases with the heating rate. The weight losses validate the polymer identification. The heating rate does not appear to affect the weight loss percentage. However, the weight loss percentage varies with the polymer fraction that degrades at that moment.

3.1.1.3. Modeling the degradation of EVA/PS. The EVA model used in the remainder of this study was developed during a prior study of separate polymers [20]. EVA decomposes with two weight losses according to a series/parallel scheme. We have shown that it is highly consistent with our experimental values for EVA degradation:

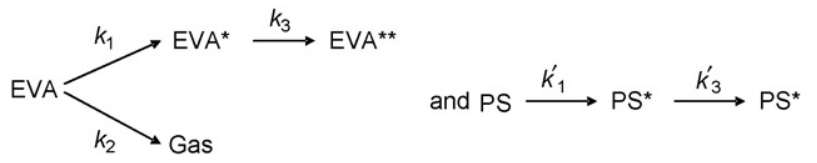

$\mathrm{dEVA}=-k_{1} \exp \left(\frac{-E a 1}{R T}\right)[\mathrm{EVA}]-k_{2} \exp \left(\frac{-E a 2}{R T}\right)[\mathrm{EVA}]$

$\mathrm{dEVA} *=k_{1} \exp \left(\frac{-E a 1}{R T}\right)[\mathrm{EVA}]-k_{3} \exp \left(\frac{-E a 3}{R T}\right)[\mathrm{EVA} *]$
Table 5

Activation energies and pre-exponential factors determined for EVA/PS mixture

\begin{tabular}{lll}
\hline Compound & $\begin{array}{l}\text { Pre-exponential } \\
\text { factor }\left(\mathrm{min}^{-1}\right)\end{array}$ & $\begin{array}{l}\text { Activation energy } \\
\left(\mathrm{J} \mathrm{mol}^{-1}\right)\end{array}$ \\
\hline EVA & $A 1=7.46 \times 10^{16}$ & $E a 1=1.85 \times 10^{5}$ \\
& $A 2=1.02 \times 10^{17}$ & $E a 2=2.09 \times 10^{5}$ \\
& $A 3=9.19 \times 10^{19}$ & $E a 3=2.71 \times 10^{5}$ \\
PS & $A 1=1.75 \times 10^{15}$ & $E a 1=1.77 \times 10^{5}$ \\
& $A 3=5.04 \times 10^{16}$ & $E a 3=2.21 \times 10^{5}$
\end{tabular}

$\mathrm{dEVA}_{\text {total }}=\mathrm{dEVA}+\mathrm{dEVA} *$

$\mathrm{dEVA}_{\text {total,mélange }}=\left(\mathrm{EVA}_{\mathrm{wt}} \%\right) \mathrm{dEVA}_{\text {total }}$

$\mathrm{dPS}=-k_{1}^{\prime} \exp \left(\frac{-E a 1^{\prime}}{R T}\right)[\mathrm{PS}]$

$\mathrm{dPS} *=k_{1}^{\prime} \exp \left(\frac{-E a 1^{\prime}}{R T}\right)[\mathrm{PS}]-k_{3}^{\prime} \exp \left(\frac{-E a 3^{\prime}}{R T}\right)[\mathrm{PS} *]$

$\mathrm{dPS}_{\text {total }}=\mathrm{dPS}+\mathrm{dPS} *$

$\mathrm{dPS}_{\text {total,mixture }}=(\mathrm{PS} \mathrm{wt} \%) \mathrm{dPS}_{\text {total }}$

$\mathrm{d}\left(\frac{\text { EVA }}{\text { PS mixture }}\right)=\mathrm{dEVA}_{\text {total,mixture }}+\mathrm{dPS}_{\text {total,mixture }}$

The data concerning the pre-exponential factors and the activation energy are summarized in Table 5.

By compiling the experimental results obtained for different EVA/PS mixtures (and EVA/PVC) at different heating rates we

Table 6

Chronological order of disappearance of reactants and intermediate reaction products

\begin{tabular}{|c|c|c|c|}
\hline Mixture & $\begin{array}{l}\text { Proportions } \\
\text { (\%) (EVA/PS } \\
\text { or EVA/PVC) }\end{array}$ & $\begin{array}{l}\text { Heating rate } \\
\left({ }^{\circ} \mathrm{C} \min ^{-1}\right)\end{array}$ & Order of disappearance \\
\hline \multirow[t]{3}{*}{ EVA/PS } & $\begin{array}{l}25 / 75 \\
50 / 50 \\
75 / 25\end{array}$ & 5 & $\begin{array}{l}\text { EVA/PS/PS*/EVA* } \\
\text { EVA/PS/PS*/EVA* } \\
\text { EVA/PS/PS*/EVA* }\end{array}$ \\
\hline & $\begin{array}{l}25 / 75 \\
50 / 50 \\
75 / 25\end{array}$ & 10 & $\begin{array}{l}\text { EVA/PS/PS*/EVA* } \\
\text { EVA/PS/PS*/EVA* } \\
\text { PS/EVA/PS*/EVA* }\end{array}$ \\
\hline & $\begin{array}{l}25 / 75 \\
\\
50 / 50 \\
75 / 25\end{array}$ & 20 & $\begin{array}{l}\mathrm{PS} / \mathrm{EVA} / \mathrm{EVA} * / \mathrm{PS} *(\text { Rejected, } \\
\text { too many errors) } \\
\text { EVA/PS/PS*/EVA* } \\
\text { PS/EVA/PS*/EVA* }\end{array}$ \\
\hline \multirow[t]{3}{*}{ EVA/PVC } & $\begin{array}{l}25 / 75 \\
50 / 50 \\
75 / 25\end{array}$ & 5 & $\begin{array}{l}\mathrm{PVC} / \mathrm{EVA} / \mathrm{EVA}^{*} / \mathrm{PVC} \\
\mathrm{PVC} / \mathrm{EVA} / \mathrm{PVC} * / \mathrm{EVA} * \\
\mathrm{EVA} / \mathrm{PVC} / \mathrm{PVC} * / \mathrm{EVA}^{*}\end{array}$ \\
\hline & $\begin{array}{l}25 / 75 \\
50 / 50 \\
75 / 25\end{array}$ & 10 & $\begin{array}{l}\text { EVA/PVC/PVC*/EVA* } \\
\text { EVA/PVC/PVC*/EVA* } \\
\text { EVA/PVC/PVC*/EVA* }\end{array}$ \\
\hline & $\begin{array}{l}25 / 75 \\
50 / 50 \\
75 / 25\end{array}$ & 20 & $\begin{array}{l}\mathrm{PVC} / \mathrm{EVA} / \mathrm{PVC}^{*} / \mathrm{EVA}^{*} \\
\mathrm{PVC} / \mathrm{EVA} / \mathrm{PVC}^{*} / \mathrm{EVA}^{*} \\
\mathrm{PVC} / \mathrm{EVA} / \mathrm{PVC}^{*} / \mathrm{EVA}^{*}\end{array}$ \\
\hline
\end{tabular}


Table 7

Results obtained in MATLAB for 1:3 EVA/PS mixture at $10{ }^{\circ} \mathrm{C} \min ^{-1}$

\begin{tabular}{llll}
\hline Coefficient & $\begin{array}{l}\text { Published } \\
\text { value }\end{array}$ & $\begin{array}{l}\text { Calculated } \\
\text { value }\end{array}$ & $\begin{array}{l}\text { Correlation } \\
\text { factor }\end{array}$ \\
\hline$A 1 \mathrm{EVA}\left(\mathrm{min}^{-1}\right)$ & $4.00 \times 10^{17}$ & $8.43 \times 10^{16}$ & 0.0001 \\
$A 2 \mathrm{EVA}\left(\mathrm{min}^{-1}\right)$ & $7.50 \times 10^{16}$ & $7.71 \times 10^{16}$ & 0.0004 \\
$A 3 \mathrm{EVA}\left(\mathrm{min}^{-1}\right)$ & $1.00 \times 10^{19}$ & $8.43 \times 10^{18}$ & 0.00008 \\
Ea1EVA $\left(\mathrm{J} \mathrm{mol}^{-1}\right)$ & $1.98 \times 10^{5}$ & $1.97 \times 10^{5}$ & 0.003 \\
Ea2EVA $\left.(\mathrm{J} \mathrm{mol})^{-1}\right)$ & $2.08 \times 10^{5}$ & $2.16 \times 10^{5}$ & 0.0005 \\
Ea3EVA $\left(\mathrm{J} \mathrm{mol}^{-1}\right)$ & $2.72 \times 10^{5}$ & $2.73 \times 10^{5}$ & 0.0008 \\
$A 1 \mathrm{PS}\left(\mathrm{min}^{-1}\right)$ & $2.09 \times 10^{14}$ & $2.06 \times 10^{14}$ & 0.0004 \\
$A 3 \mathrm{PS}\left(\mathrm{min}^{-1}\right)$ & $2.70 \times 10^{16}$ & $3.09 \times 10^{16}$ & 0.0012 \\
Ea1PS $\left(\mathrm{J} \mathrm{mol}^{-1}\right)$ & $1.92 \times 10^{5}$ & $1.89 \times 10^{5}$ & 0.0007 \\
Ea3PS $\left(\mathrm{J} \mathrm{mol}^{-1}\right)$ & $2.16 \times 10^{5}$ & $2.13 \times 10^{5}$ & 0.0039 \\
\hline
\end{tabular}

determined the order of disappearance of each compound, as summarized in Table 6 .

The experimental results and the characteristic points on the DTA/TGA graphs were used to recalculate the parameters of the kinetic Eqs. (2)-(10). Table 7 lists these values, compared with published data.

The results in the preceding table show a very acceptable agreement between the values in the literature and our computed values. The correlation factor reflects the accuracy of the values obtained, as determined by a least-squares method comparing the experimental and calculated weight values. The closer the factor to zero, the better the consistency between the theoretical and experimental data.

The hypothesis of independent degradation is equivalent to a simple addition of each of the individual polymer degradation values; analyzing the weight variations over time confirmed our hypotheses. The theoretical and experimental weight variations versus time are plotted on the same graph. Fig. 1 shows the weight loss versus time for the 1:3 EVA/PS mixture and a heating rate of $10{ }^{\circ} \mathrm{C} \mathrm{min}^{-1}$, illustrating the agreement of the curves: the kinetic model is validated for the EVA/PS mixture. The degradation of the mixed polymers is equal to the sum of the degradations for the individual polymers: they thus appear to be degraded without any interactions.

Analysis of the weight losses, degradation temperatures, and DTG values for the EVA/PS mixture thus confirms the hypothesis that the polymers are degraded independently. The curves computed using MATLAB are very similar to the experimental curves.

The three weight losses observed on the curves correspond to the first EVA loss, the PS loss, and the second EVA loss, respectively. Modeling the pyrolysis kinetics of the mixture

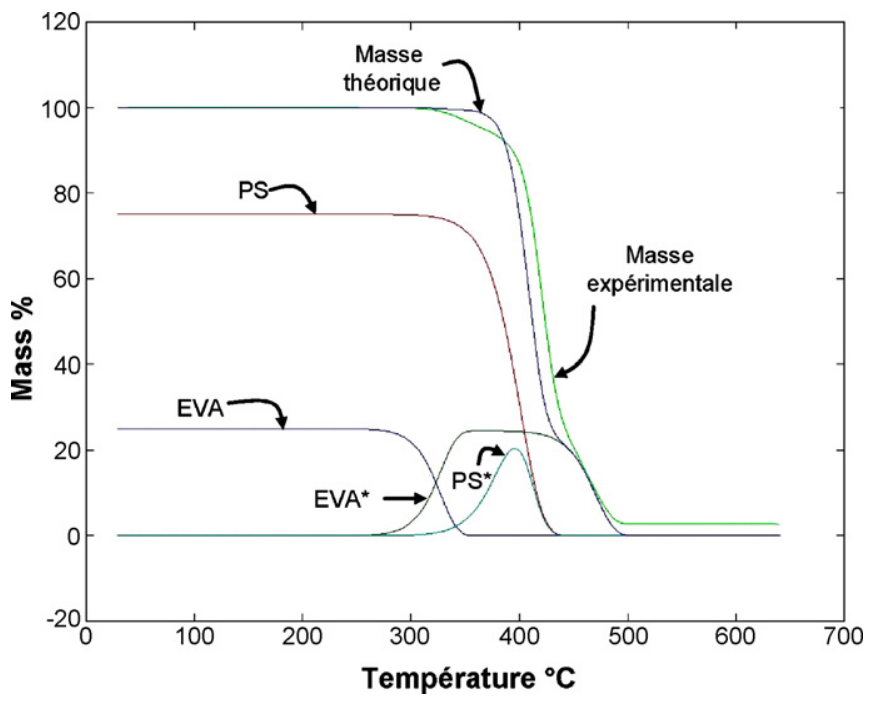

Fig. 1. Theoretical and experimental weight losses vs. time for the 1:3 EVA/PS mixture at a heating rate of $10{ }^{\circ} \mathrm{C} \mathrm{min}^{-1}$.

reaction schemes using MATLAB confirms the experimental results, demonstrating the hypothesis of independent degradation.

\subsubsection{EVA/PVC mixture}

3.1.2.1. Experimental results for EVA and PVC alone. The results for EVA alone were detailed in Section 3.1.1.1.

Table 8 shows the temperatures of the DTG peaks observed during pyrolysis of pure PVC. These temperatures constitute the reference values for identifying the compounds that degrade during pyrolysis of the mixed polymers. As before, the table indicates the DTG peak temperatures, the DTG percentage, and the weight losses versus the heating rates for PVC alone.

Three weight losses are observed during the degradation of PVC alone at heating rates up to $20{ }^{\circ} \mathrm{C} \mathrm{min}^{-1}$. With a heating rate of $30{ }^{\circ} \mathrm{C} \mathrm{min}{ }^{-1}$, however, only two peaks can be observed. At this fast rate the degradations are recorded simultaneously and the peaks are superimposed.

It may already be noted at this point that PVC and EVA share the same temperature ranges.

3.1.2.2. EVA/PVC mixture: analysis of experimental results. Table 9 shows the TGA results obtained on mixtures with various EVA/PVC ratios and heating rates.

The thermogravimetric curve shows three weight losses for this mixture. The measured weight losses are expressed as a

Table 8

Weight losses, DTG values, and DTG peak temperatures for pure PVC

\begin{tabular}{|c|c|c|c|c|c|c|c|c|c|}
\hline \multirow{2}{*}{$\begin{array}{l}\text { Heating rate } \\
\left({ }^{\circ} \mathrm{C} \min ^{-1}\right)\end{array}$} & \multicolumn{3}{|c|}{ DTG peak temperature $\left({ }^{\circ} \mathrm{C}\right)$} & \multicolumn{3}{|c|}{ DTG value $\left(\% \min ^{-1}\right)$} & \multicolumn{3}{|c|}{ Weight loss (\%) } \\
\hline & $\begin{array}{l}\text { First } \\
\text { loss }\end{array}$ & $\begin{array}{l}\text { Second } \\
\text { loss }\end{array}$ & $\begin{array}{l}\text { Third } \\
\text { loss }\end{array}$ & $\begin{array}{l}\text { First } \\
\text { loss }\end{array}$ & $\begin{array}{l}\text { Second } \\
\text { loss }\end{array}$ & $\begin{array}{l}\text { Third } \\
\text { loss }\end{array}$ & $\begin{array}{l}\text { First } \\
\text { loss }\end{array}$ & $\begin{array}{l}\text { Second } \\
\text { loss }\end{array}$ & $\begin{array}{l}\text { Third } \\
\text { loss }\end{array}$ \\
\hline 5 & 270 & 325 & 458 & -9.5 & -1.2 & -2.2 & 56.3 & 10.9 & 25.6 \\
\hline 10 & 283 & 336 & 470 & -15.5 & -2.3 & -3.9 & 58.1 & 10 & 25.6 \\
\hline 20 & 300 & 350 & 480 & -22.3 & -6.3 & -6.5 & 58 & 10.6 & 24.4 \\
\hline 30 & 312 & - & 483 & -26.6 & - & -8.6 & 56.3 & 13.1 & 23.1 \\
\hline
\end{tabular}


Table 9

Summary of graphical readout of experimental curves for EVA/PVC mixture: weight losses, DTG values, and DTG peak temperatures

\begin{tabular}{|c|c|c|c|c|c|c|c|c|c|c|}
\hline \multirow[t]{2}{*}{ Mixture } & \multirow{2}{*}{$\begin{array}{l}\text { Heating rate } \\
\left({ }^{\circ} \mathrm{C} \min ^{-1}\right)\end{array}$} & \multicolumn{3}{|c|}{ DTG peak temperature $\left({ }^{\circ} \mathrm{C}\right)$} & \multicolumn{3}{|c|}{ DTG value $\left(\% \min ^{-1}\right)$} & \multicolumn{3}{|c|}{ Weight loss (\%) } \\
\hline & & $\begin{array}{l}\text { First } \\
\text { loss }\end{array}$ & $\begin{array}{l}\text { Second } \\
\text { loss }\end{array}$ & $\begin{array}{l}\text { Third } \\
\text { loss }\end{array}$ & $\begin{array}{l}\text { First } \\
\text { loss }\end{array}$ & $\begin{array}{l}\text { Second } \\
\text { loss }\end{array}$ & $\begin{array}{l}\text { Third } \\
\text { loss }\end{array}$ & $\begin{array}{l}\text { First } \\
\text { loss }\end{array}$ & $\begin{array}{l}\text { Second } \\
\text { loss }\end{array}$ & $\begin{array}{l}\text { Third } \\
\text { loss }\end{array}$ \\
\hline \multirow[t]{4}{*}{$25 \%$ EVA } & 5 & 265 & 333 & 464 & -7.4 & -1.1 & -3.9 & 44.4 & 13.1 & 36.3 \\
\hline & 10 & 231 & 336 & 475 & -12.2 & -2.2 & -7.4 & 45 & 13.1 & 36.3 \\
\hline & 20 & 346 & 355 & 483 & -17.6 & -4.6 & -12 & 45 & 15 & 34.4 \\
\hline & 30 & 308 & - & 494 & -21.4 & - & -15.6 & 43.8 & 10.6 & 38.1 \\
\hline \multirow[t]{4}{*}{$50 \%$ EVA } & 5 & 265 & 330 & 465 & -4.75 & -1.4 & -6.25 & 30 & 13.3 & 50.7 \\
\hline & 10 & 277 & 347 & 476 & -8.8 & -2.48 & -11.2 & 36.3 & 11.9 & 48.9 \\
\hline & 20 & 294 & 350 & 487 & -12.9 & -5 & -18.3 & 31.9 & 15 & 48.1 \\
\hline & 30 & 308 & - & 494 & -15.4 & - & -22.3 & 32.5 & 13.1 & 51.3 \\
\hline \multirow[t]{4}{*}{$75 \%$ EVA } & 5 & 268 & 328 & 464 & -2.3 & -1.6 & -8.15 & 16.7 & 18 & 62 \\
\hline & 10 & 278 & 346 & 476 & -4.3 & -3.1 & -14.5 & 18 & 17 & 61.3 \\
\hline & 20 & 300 & 358 & 488 & -6.8 & -5.5 & -23.5 & 16 & 21.6 & 62.4 \\
\hline & 30 & 308 & 369 & 494 & -8.3 & -7.5 & -29.1 & 18 & 19 & 60.3 \\
\hline
\end{tabular}

percentage of the initial weight. When the sum is not equal to 100 , this implies that a solid residue remained in the crucible after pyrolysis.

The first degradation with a maximum rate between 260 and $308{ }^{\circ} \mathrm{C}$ corresponds to the first PVC degradation: this is the only weight loss between 270 and $300{ }^{\circ} \mathrm{C}$. The second weight loss occurs between 330 and $370{ }^{\circ} \mathrm{C}$; the second degradation occurs near $350{ }^{\circ} \mathrm{C}$. This temperature corresponds both to the first EVA weight loss and the second PVC weight loss. The last degradation occurs between 460 and $500{ }^{\circ} \mathrm{C}$, practically the same temperature range $\left(450-475^{\circ} \mathrm{C}\right)$ as two degradations for the individual compounds: the third degradation for PVC and the second for EVA. The DTG values were analyzed in the same way as for the EVA/PS mixture to validate the hypothetical order of degradation (Table 6). The calculations confirmed that the first weight loss corresponded to the first PVC degradation, and identified the compounds degraded during the final weight loss, but did not confirm the second PVC degradation. It is more difficult to compare the DTG values and the degraded polymer fraction for a given weight loss. Only the analysis of the first weight loss appears to confirm the hypothesis of PVC degradation: the value increases with the proportion of PVC in the mixture. For the second weight loss, all the values are of comparable magnitude, and for the last weight loss - for which we assumed simultaneous degradation of both polymers - it is difficult to perform the analysis. Nevertheless, as the DTG value increases with the percentage of EVA in the mixture, the effect of EVA appears to predominate.

As with the EVA/PS mixture, increasing the heating rate results in faster degradation of the polymer, while the heating rate does not appear to affect the weight loss percentage. Examining the weight loss percentage and the polymer fraction that degrades at the moment of the first weight loss shows that both values vary in the same way. For the final weight loss, the hypothesis that EVA has a greater effect than PVC during this degradation is confirmed. Fig. 2 shows the profiles obtained for a heating rate of $20^{\circ} \mathrm{C} \mathrm{min}{ }^{-1}$.

The curves in Fig. 2 indicate that the first degradation, with a maximum rate near $300{ }^{\circ} \mathrm{C}$, can be attributed to the first PVC weight loss, which occurs in this temperature range for the pure polymer. The second degradation occurs near $350{ }^{\circ} \mathrm{C}$ : this temperature corresponds both to the first EVA weight loss and the second PVC weight loss. The third degradation occurs near $480{ }^{\circ} \mathrm{C}$, i.e. in the temperature range corresponding both to the second EVA weight loss and the final PVC weight loss. The phenomena involved are complex and cannot be interpreted simply because the degradation ranges of the pure polymers are superimposed. FTIR analysis of the pyrolysis gases will provide conclusive evidence concerning the actual progress of this degradation phase.

3.1.2.3. Modeling the degradation of EVA/PVC. The kinetic model for EVA is the same as defined above with PS. The following model is used for PVC:

$\mathrm{PVC} \stackrel{k_{1}^{\prime}}{\longrightarrow} a \mathrm{HCl}+b \mathrm{PVC} *$

$b \mathrm{PVC} * \stackrel{k_{2}^{\prime}}{\longrightarrow} c \mathrm{G}+e \mathrm{RS}$

$e \mathrm{RS} \stackrel{k_{3}^{\prime}}{\longrightarrow} f \mathrm{G}^{\prime}+g \mathrm{RS} *$

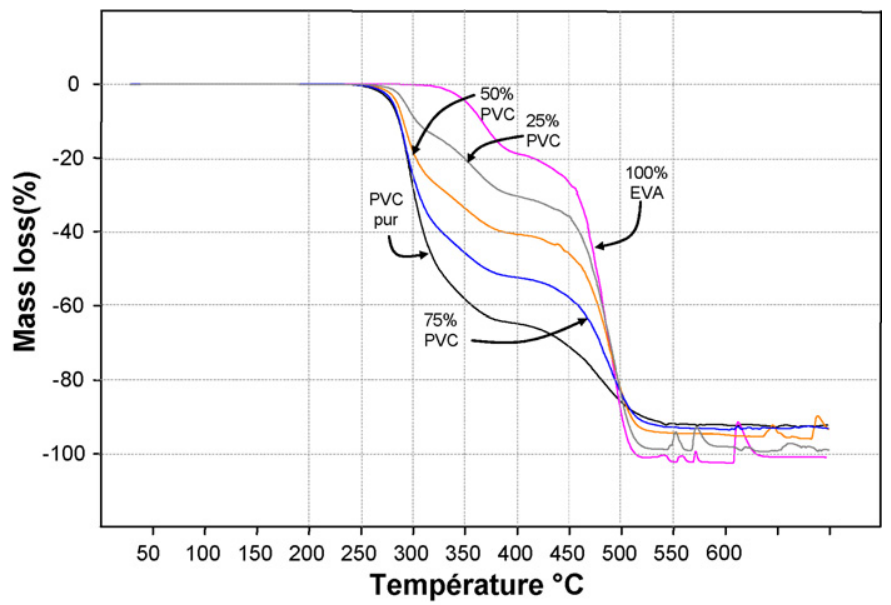

Fig. 2. Superimposed TGA curves for pure EVA, pure PVC and three different EVA/PVC mixtures. 
The kinetic equations are identical for EVA degradation (Eqs. (2)-(10)) and as follows for PVC degradation:

$$
\begin{aligned}
& \mathrm{dPVC}=-k_{1}^{\prime} \exp \left(\frac{-E a 1^{\prime}}{R T}\right)[\mathrm{PVC}] \\
& \mathrm{dPVC} *=b\left(k_{1}^{\prime} \exp \left(\frac{-E a 1^{\prime}}{R T}\right)[\mathrm{PVC}]\right. \\
& \left.-k_{2}^{\prime} \exp \left(\frac{-E a 2^{\prime}}{R T}\right)[\mathrm{PVC} *]\right)
\end{aligned}
$$

$\mathrm{dRS}=e\left(k_{2}^{\prime} \exp \left(\frac{-E a 2^{\prime}}{R T}\right)[\mathrm{PVC} *]-k_{3}^{\prime} \exp \left(\frac{-E a 3^{\prime}}{R T}\right)[\mathrm{RS}]\right)$

$\mathrm{dRS} *=g\left(k_{3}^{\prime} \exp \left(\frac{-E a 3^{\prime}}{R T}\right)[\mathrm{RS}]\right)$

$\mathrm{dPVC}_{\text {total }}=\mathrm{dPVC}+\mathrm{dPVC} *+\mathrm{dRS}$

$\mathrm{dPVC}_{\text {total,mixture }}=(\mathrm{PVC}$ wt $\%) \mathrm{dPVC}_{\text {total }}$

As in the case of EVA/PS mixtures, assuming independent degradation is equivalent to the simple addition of the pure polymer models:

$\mathrm{d}\left(\frac{\mathrm{EVA}}{\text { PVC mixture }}\right)=\mathrm{dEVA}_{\text {total,mixture }}+\mathrm{dPVC}_{\text {total,mixture }}$

The validity of the model proposed for EVA/PVC mixtures (i.e. independent degradation) was verified by simulation in MATLAB and compared with experimental results. Fig. 3 shows the curves obtained.

The calculated and experimental curves for each mixture proportion and heating rate are plotted on the same graph to facilitate comparisons. Fig. 3 appears to contradict the hypothetical independence of polymer degradation. As the kinetic models used for PVC and EVA alone were validated by the experimental values obtained during the previous study, the

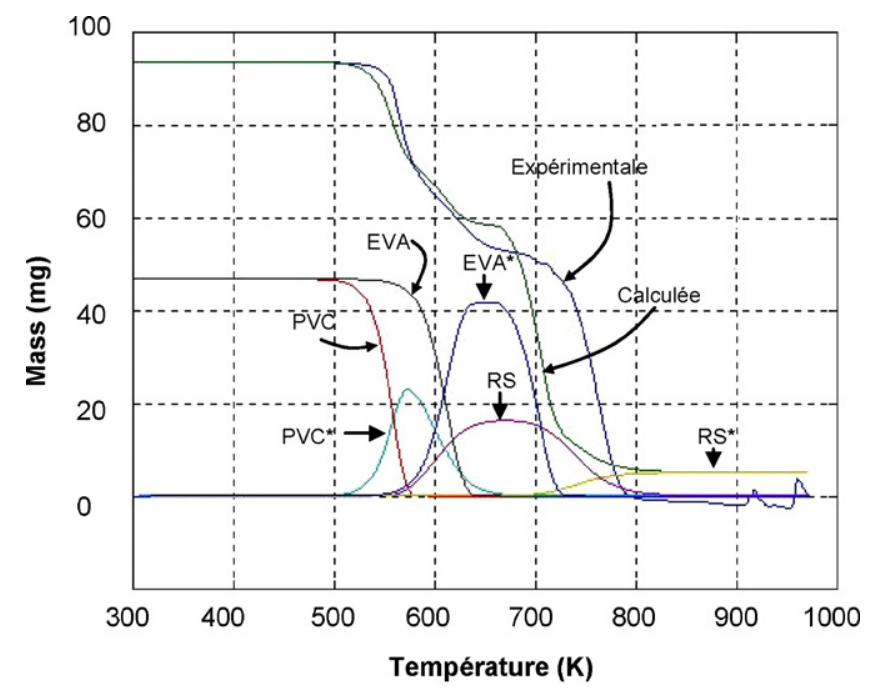

Fig. 3. Experimental and calculated curves for EVA/PVC mixture.
Table 10

Maximum relative weight loss errors between experimental and calculated curves

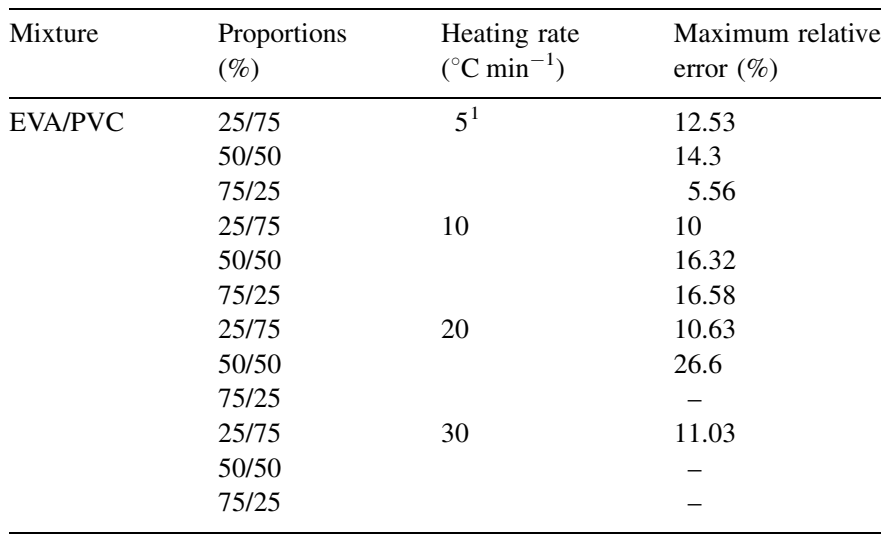

inconsistency between the experimental and calculated results for the mixture can only be explained by assuming that the behavior of the mixed polymers is interdependent. The MATLAB simulation refutes the hypothesis of independent degradation for the EVA/PVC mixture. It is reasonable to assume an interaction of PVC with the degradation of EVA during pyrolysis of the mixture. A more detailed analysis of the relative errors $\left(\left(\left|\mathrm{Wt}_{\exp }-\mathrm{Wt}_{\text {calc }}\right|\right) / \mathrm{Wt}_{\mathrm{exp}}\right)$ also corroborates these conclusions. Table 10 indicates the maximum relative weight loss errors.

\subsubsection{EVA/cellulose mixture}

3.1.3.1. Experimental results for EVA and cellulose alo$n e$. The results for EVA alone were detailed in Section 3.1.1.1.

Table 11 shows the temperatures of the DTG peaks observed during pyrolysis of pure cellulose. These temperatures constitute the reference values for identifying the compounds that degrade during pyrolysis of the mixed polymers. As before, the table indicates the DTG peak temperatures, the DTG percentage, and the weight losses versus the heating rates for cellulose alone.

For the assessment of cellulose alone, the experimental results cover two heating rates: 10 and $30{ }^{\circ} \mathrm{C} \mathrm{min}{ }^{-1}$. A single weight loss is observed. The weight loss on the thermogravimetric curve is characterized by a very steep slope. The cellulose peak is situated at about $350{ }^{\circ} \mathrm{C}$ (Table 11), which coincides with the first EVA peak.

Based only on the thermogravimetric data, it is already clear that it will be difficult to determine the proportion of each polymer in the weight loss signal for pyrolysis of the mixture.

Table 11

Weight losses, DTG values, and DTG peak temperatures for pure cellulose

\begin{tabular}{llll}
\hline $\begin{array}{l}\text { Heating rate } \\
\left({ }^{\circ} \mathrm{C} \mathrm{min}{ }^{-1}\right)\end{array}$ & $\begin{array}{l}\text { DTG peak } \\
\text { temperature }\left({ }^{\circ} \mathrm{C}\right) \\
(\text { weight loss) }\end{array}$ & $\begin{array}{l}\text { DTG value } \\
\left(\% \mathrm{~min}^{-1}\right) \\
(\text { weight loss) }\end{array}$ & $\begin{array}{l}\text { Weight loss }(\%) \\
(\text { weight loss) }\end{array}$ \\
\hline 10 & 345 & -23.3 & 83 \\
30 & 364 & -37 & 83 \\
\hline
\end{tabular}


Table 12

Weight losses, DTG values, and DTG peak temperatures for the EVA/cellulose mixture

\begin{tabular}{|c|c|c|c|c|c|c|c|}
\hline \multirow[t]{2}{*}{ Mixture } & \multirow{2}{*}{$\begin{array}{l}\text { Heating rate } \\
\left({ }^{\circ} \mathrm{C} \min ^{-1}\right)\end{array}$} & \multicolumn{2}{|c|}{ DTG peak temperature $\left({ }^{\circ} \mathrm{C}\right)$} & \multicolumn{2}{|c|}{ DTG value $\left(\% \min ^{-1}\right)$} & \multicolumn{2}{|c|}{ Weight loss $(\%)$} \\
\hline & & First loss & Second loss & First loss & Second loss & First loss & Second loss \\
\hline \multirow[t]{2}{*}{$50 \%$ EVA } & 10 & 346 & 476 & -13 & -9.1 & 54.4 & 39.4 \\
\hline & 30 & 368 & 492 & -22.9 & -18.9 & 55.6 & 39.4 \\
\hline
\end{tabular}

3.1.3.2. EVA/cellulose mixture. Table 12 shows the TGA results obtained on mixtures with various EVA/cellulose ratios and heating rates.

Table 12 gives the experimental results for heating rates of 10 and $30{ }^{\circ} \mathrm{C} \min ^{-1}$ with a $1: 1$ mixture. Two weight losses were observed. The first degradation, with a maximum rate near $350{ }^{\circ} \mathrm{C}$, can be identified as the superimposition of the first EVA weight loss and the cellulose weight loss, both of which occur near this temperature for the pure compounds. The second degradation occurs at about $480{ }^{\circ} \mathrm{C}$, which corresponds to the temperature of the final EVA weight loss.

3.1.3.3. Modeling the degradation of EVA/cellulose. Once again, we postulated the independent degradation of the compounds, corresponds simply in the model to the sum of each of the degradation steps for the individual polymers. The selected kinetic models are again taken from the preceding study [33]. For EVA we conserved the model previously used for the EVA/PS and EVA/PVC mixtures.

Cellulose is assumed to decompose according to two parallel reactions as shown in the following Broido-Shafizadeh reaction scheme:
Assuming the kinetics are independent, the following expression is applied:

$\mathrm{d}\left(\frac{\text { EVA }}{\text { cellulose mixture }}\right)$

$=\mathrm{dEVA}_{\text {total,mixture }}+\mathrm{dCellulose}_{\text {total,mixture }}$

Modeling the kinetic equations in MATLAB allowed us to compare the published theoretical models with our experimental results. To highlight comparison, the theoretical and experimental weight variations versus time are plotted on the same graph Fig. 4.

The above figure reveals a difference between the experimental and calculated curves. Although not as great as the difference observed for the EVA/PVC mixture, it suggests that interactions also occur between the compounds in this mixture, and particular that acetic acid affects the degradation of cellulose. EVA, which produces acetic acid when degraded, could affect the cellulose molecule and accelerate its degradation (note the difference between the experimental and calculated curves).

The degradation curves for pure cellulose, pure EVA and a 1:1 mixture of the two are superimposed in Fig. 5. Pure

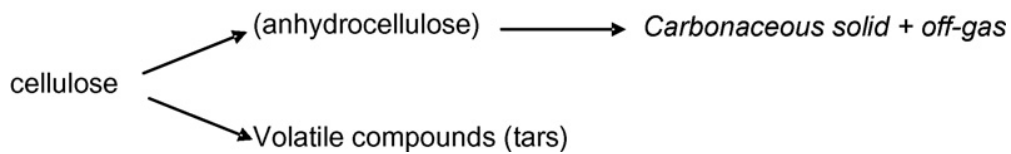

Complex kinetic models are found in the literature based on the multistage reaction mechanism described above. Most often, however, the expression for the kinetics of thermal degradation is limited to a single step [32] and the kinetics can be summarized by expression (18). This study showed that most suitable basis for modeling the kinetics of cellulose degradation is the Prout-Tomkins equation, which we have adopted here. The results obtained with the model deviate from the experimental findings for the last portion of the curve, although the overall results are relatively close to reality.

The kinetic equations for cellulose are thus the following:

$\mathrm{dCellulose}=k_{0} \exp \left(\frac{-E}{R T}\right)(1-[$ Cellulose $])[\text { Cellulose }]^{0.5}$

$\mathrm{dCellulose}_{\text {total,mixture }}=($ Cellulose $\mathrm{wt} \%) \mathrm{dCellulose}$ cellulose degrades to about $85 \%$; the total weight loss of the mixture was $95 \%$. The mixture curve should be found exactly halfway between the curves for the pure compounds $(1: 1$ proportions), but in fact the cellulose in the mixture was degraded more than when it was pure. The difference is therefore due to enhanced cellulose degradation, which could be attributable to acetic acid, as suggested above.

The MATLAB simulation thus contradicts the hypothesis of independent degradation for the EVA/cellulose mixture. FTIR analysis will provide a better understanding of the interaction observed in the mixture, and identify the reasons for the dependent degradation.

\section{Analysis of FTIR results for evolved pyrolysis gases}

The gas cell of the infrared spectrophotometer was connected to the outlet of the thermograph oven by a temperature-regulated transfer line. The FTIR analyzer via TimeBase provides the 


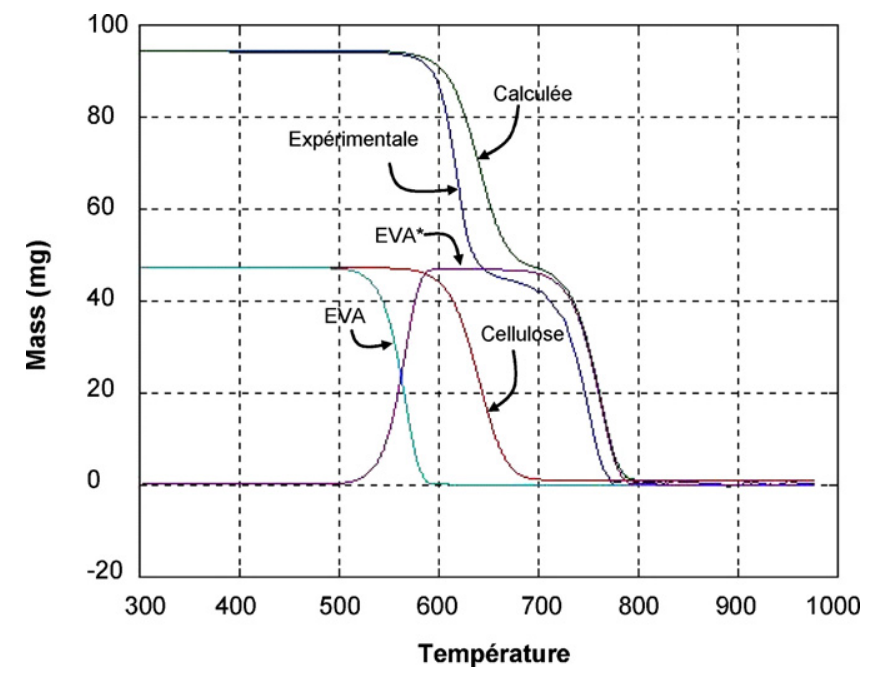

Fig. 4. Experimental and calculated curves for EVA/cellulose mixture.

Gram-Schmidt profile of pyrolysis gas absorption versus time. It is interesting to be able to relate the FTIR spectra analysis results to the weight variations recorded on the thermogram. We can express the relation between the time on the Gram-Schmidt profile corresponding to a recorded FTIR spectrum for each time value $t$, and the sample temperature indicated on the thermogram. The Gram-Schmidt recording is electronically synchronized to start at the same time the thermal analyzer begins heating, designated $t_{0}$ for each test.

The temperature is then expressed versus time as follows:

$T=\frac{[(\text { tir } / \text { trs }) \beta]}{60}$

- tir: time in seconds corresponding to an FTIR spectrum obtained from the Gram-Schmidt record

- trs: transfer time in seconds of the gas evolved during pyrolysis from the TGA to the FTIR gas cell (depending on the system setup and the vector gas flow rate, experimentally measured as $110 \mathrm{~s}$ ).

- $\beta$ heating rate $\left({ }^{\circ} \mathrm{C} \min ^{-1}\right)$.

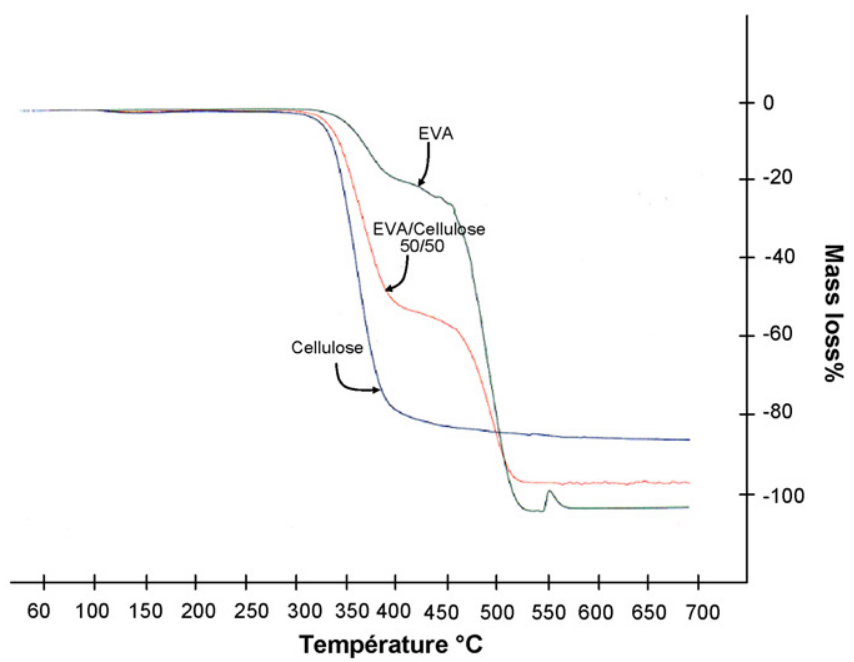

Fig. 5. Experimental degradation curves for pure cellulose, pure EVA and a 1:1 mixture of the two.
- $T^{\circ} \mathrm{C}$ sample temperature recorded on the thermogram.

The Fourier transform for each time $t$ on the Gram-Schmidt profile yields the corresponding IR spectra, i.e. the characteristic curve of absorbance versus wave number for the products detected as they transited through the FTIR cell at that exact time. The resulting spectra were analyzed with KnowItAll by comparison with data bases containing the IR spectra of known compounds to identify the evolved gas.

Results are shown mainly for a thermal analyzer heating rate of $30{ }^{\circ} \mathrm{C} \mathrm{min}^{-1}$, although the same results were obtained in this study with $\beta=5,10$ and $20{ }^{\circ} \mathrm{C} \mathrm{min}{ }^{-1}$.

Nomenclature: In the case of mixed polymers, the polymer names are systematically given in order from the bottom to the top of the crucible. For example, all the tests designated EVAPVC were performed with EVA beneath PVC. In the following discussion, the terms "alkane or alkene compounds" (or simply "alkane" or "alkene") are used to designate the presence of saturated or unsaturated hydrocarbons, aromatic or nonaromatic, of variable length and structure, that have not been accurately identified.

\subsection{FTIR analysis of evolved gas during thermal degradation of EVA/PVC mixtures}

We have seen above that the phenomena were superimposed at temperatures near 350 and $480{ }^{\circ} \mathrm{C}$.

Our objective was to identify and discriminate between the presence of acetic acid and hydrochloric acid in the gas released by pyrolysis of the mixtures, in order to determine the degradation chronology. The evolved gases and their characteristic spectra (Fig. 8) were identified during a prior study of pure compounds [33]. The selected kinetic schemes show that acidic gas is evolved during the first step of EVA or PVC degradation.

\subsubsection{FTIR analysis of evolved gas during pyrolysis of 3:1 EVA/PVC mixtures}

Fig. 6 is the Gram-Schmidt diagram obtained by analysis with a heating rate of $30{ }^{\circ} \mathrm{C} \mathrm{min}^{-1}$.

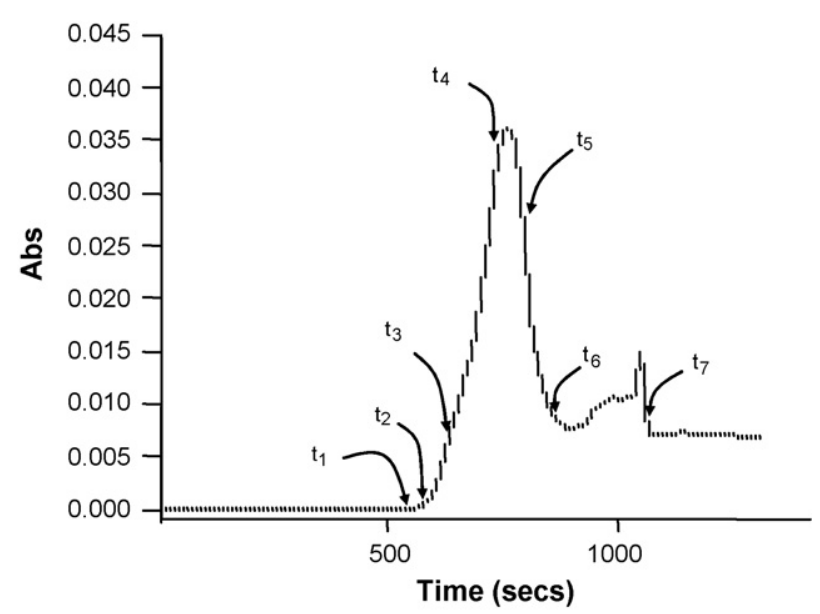

Fig. 6. Gram-Schmidt profile obtained by heating a 3:1 EVA-PVC mixture at $30{ }^{\circ} \mathrm{C} \min ^{-1}$. 
Several time values are identified in Fig. 6:

- $t_{1}=556.6 \mathrm{~s}, T_{1}=333{ }^{\circ} \mathrm{C}$. This point corresponds to the beginning of the degradation process, with IR peaks that form at about 1179 and $1798 \mathrm{~cm}^{-1}$, related to the incipient release of acetic acid. The FTIR spectrum for this point was difficult to discriminate from the background, and is not shown here.

- $t_{2}=578.4 \mathrm{~s}, T_{2}=344.2{ }^{\circ} \mathrm{C}$. This point corresponds to a more advanced stage of degradation. Acetic acid is produced, indicating the beginning of EVA degradation, but an examination of the FTIR spectra reveals the appearance of the $\mathrm{HCl}$ rotation spectrum peaks signifying that PVC degradation also occurred at this point. Fig. 7A shows the corresponding FTIR spectrum.
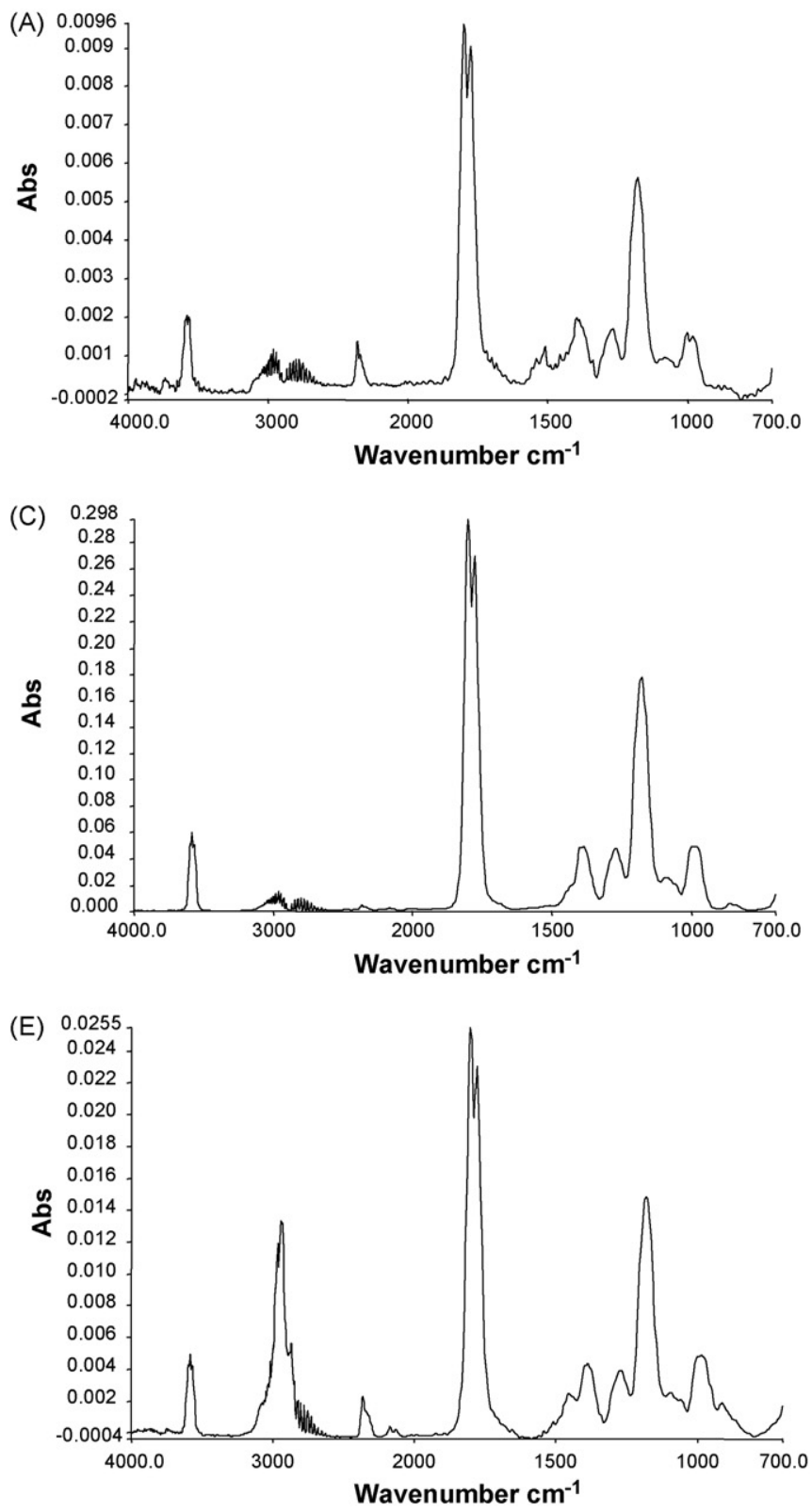

- $t_{3}=625.7 \mathrm{~s}, T_{3}=367.85{ }^{\circ} \mathrm{C}$. This point corresponds to a significant $\mathrm{HCl}$ release arising from the first PVC degradation step. Fig. 7B clearly shows a significant group of $\mathrm{HCl}$ rotation peaks. It is important to note, however, that the maximum recorded value is less than the maximum observed for the same weight of pure PVC, and that it occurs earlier. Acetic acid continues to evolve. At this point it may be noted that with pure compounds the first PVC degradation step occurs before the first EVA degradation step. This is not the case for the mixture, since acetic acid is released from the outset, indicating that $\mathrm{HCl}$ affects the degradation of EVA.

- $t_{4}=741.1 \mathrm{~s}, T_{4}=425.55{ }^{\circ} \mathrm{C}$. This point is situated slightly before the maximum peak recorded on the Gram-Schmidt profile. The corresponding FTIR spectrum, Fig. 7C, a very
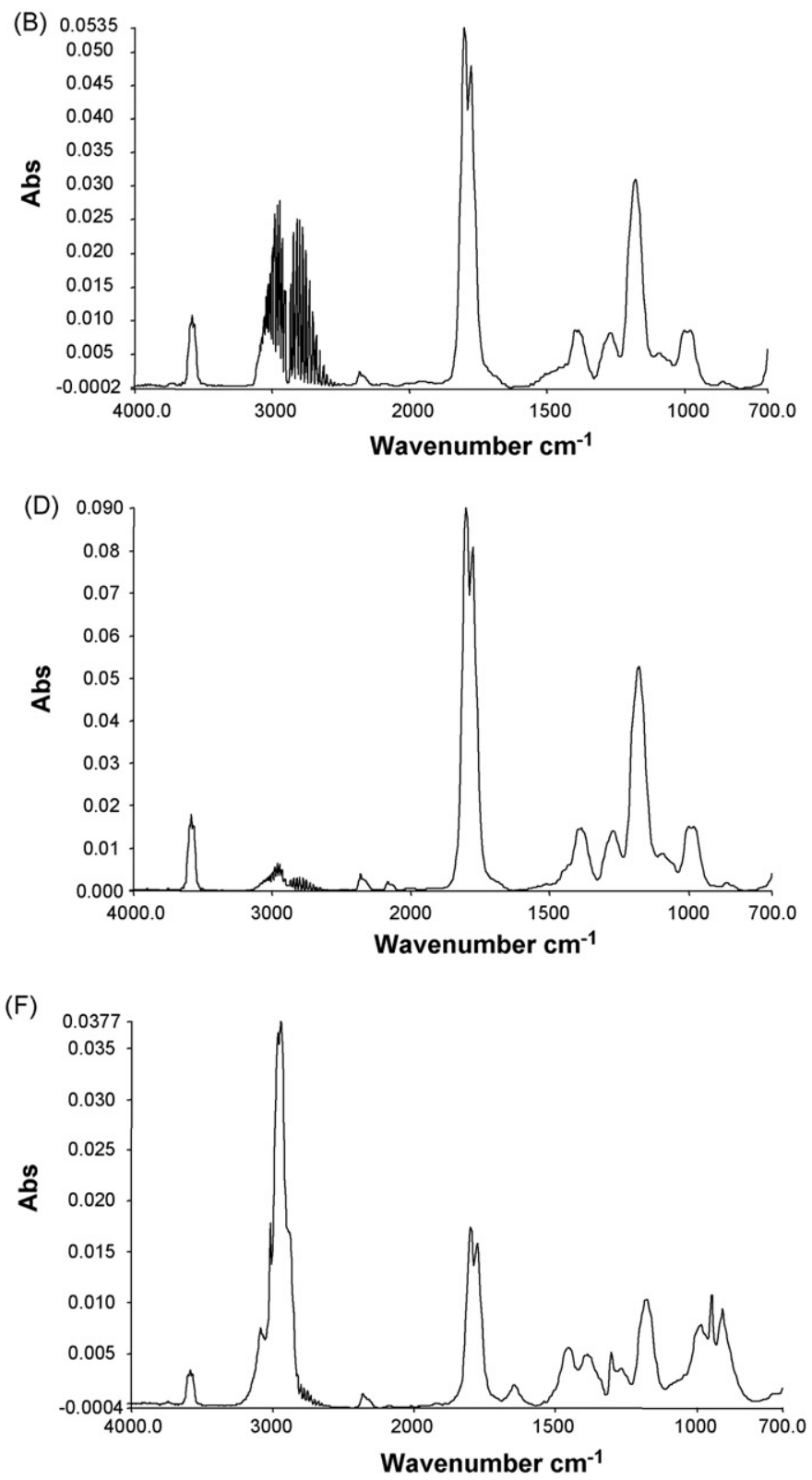

Fig. 7. IR absorption spectra recorded during degradation of the 3:1 EVA/PVC mixture for different time values on the Gram-Schmidt profile: $(\mathrm{A}) t_{2}=578 \mathrm{~s}$; (B) $t_{3}=626 \mathrm{~s} ;(\mathrm{C}) t_{4}=741 \mathrm{~s} ;$ (D) $t_{5}=797 \mathrm{~s} ; \mathrm{E}: t_{6}=869 \mathrm{~s} ;(\mathrm{F}) t_{7}=1074 \mathrm{~s}$. 

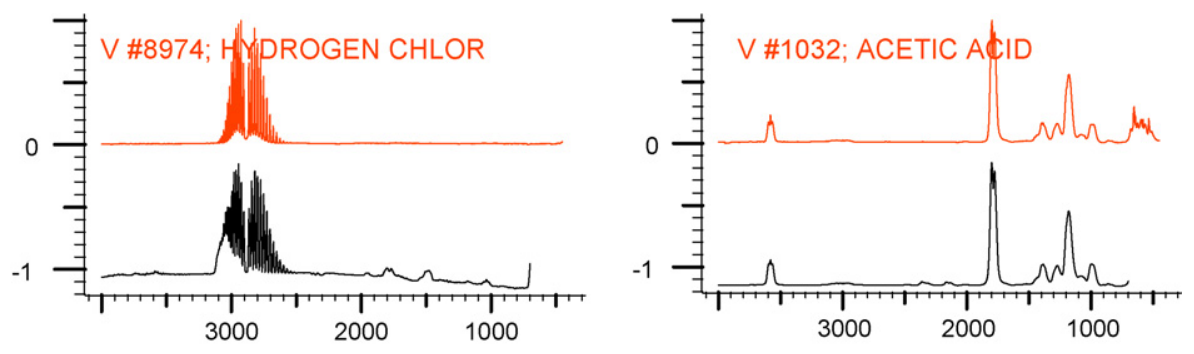

Fig. 8. IR absorption spectra recorded during degradation of PVC alone and EVA alone with reference spectra of hydrogen chloride and acetic acid.

significant reduction in the $\mathrm{HCl}$ peaks and a very significant increase in the peaks in the region around $1790 \mathrm{~cm}^{-1}$ corresponding to acetic acid. This point corresponds to the maximum evolution of these peaks.

- $t_{5}=796.5 \mathrm{~s}, T_{5}=453.2{ }^{\circ} \mathrm{C}$. This point is situated in the decreasing portion of the Gram-Schmidt profile. The $\mathrm{HCl}$ volume is appreciably smaller and alkane or alkene compounds are beginning to appear. The FTIR spectrum (Fig. 7D) corresponding to this point reveals incipient "swelling" of what remains of the $\mathrm{HCl}$ peaks: this zone is characteristic of the peaks corresponding to alkanes (2800 $\left.3000 \mathrm{~cm}^{-1}\right)$ and alkenes (3050-3150 $\left.\mathrm{cm}^{-1}\right)$.

- $t_{6}=868.5 \mathrm{~s}, T_{6}=489.3{ }^{\circ} \mathrm{C}$. This point is situated at the base of the Gram-Schmidt peak, and the corresponding FTIR spectrum (Fig. 7E) clearly shows alkane and alkene spectra. The characteristic peak of acetic acid is beginning to diminish.

- $t_{7}=1073.9 \mathrm{~s}, T_{7}=591.9^{\circ} \mathrm{C}$. This point was recorded slightly later on the Gram-Schmidt profile. The corresponding FTIR spectrum (Fig. 7F) once again shows very intense alkane and alkene peaks and a significantly lower acetic acid peak. Compared with the results obtained for pure EVA [33], this spectrum shows the rapid disappearance of acetic acid due to accelerated decomposition of EVA. In addition, the deformation of the peaks in the $1500-1700 \mathrm{~cm}^{-1}$ region (compared with EVA alone) could be related to an interaction with the $\mathrm{HCl}$ evolved at the beginning of the degradation process.

\subsubsection{FTIR analysis of evolved gas during pyrolysis of 1:1 EVA/PVC mixtures}

Fig. 9 is the Gram-Schmidt diagram obtained by analysis with a heating rate of $30{ }^{\circ} \mathrm{C} \mathrm{min}{ }^{-1}$.

A small shoulder is visible on the Gram-Schmidt profile at time $t_{3}$.

Six characteristic times are identified in Fig. 9, corresponding to the degradation stages illustrated by the FTIR diagrams in Fig. 10.

Thermal degradation of the mixture begins with a small change in the characteristic peaks of acetic acid at 604.4 s, i.e. $357.2{ }^{\circ} \mathrm{C}$ (Fig. 10A); this peak forms earlier than during the degradation of EVA alone. $\mathrm{HCl}$ then begins to form after this point (Fig. 10B); $\mathrm{HCl}$ is present simultaneously with acetic acid, for which the characteristic peaks increase in intensity. The time at point $t_{2}$ indicates a slight delay in the formation of $\mathrm{HCl}$ in the mixture compared with the result obtained for pure
PVC. In the region of the $\mathrm{HCl}$ peaks a small group of peaks appears between 3160 and $3000 \mathrm{~cm}^{-1}$.

$\mathrm{HCl}$ production continues, reaching a maximum at $t_{3}$ (Fig. 10C) then gradually diminishing while the volume of acetic acid production continues to increase until it reaches a maximum at $t_{4}$ (Fig. 10D). This point corresponds to the vertex of the peak on the Gram-Schmidt curve. The intensity of the Gram-Schmidt profile diminishes thereafter; Fig. 10E and F reveal the appearance of alkanes or alkenes. The characteristic peaks of $\mathrm{CO}$ and $\mathrm{CO}_{2}$ around $2200 \mathrm{~cm}^{-1}$ are also visible. The formation of alkanes and then of alkenes in the EVA-PVC mixture is due to the simultaneous degradation of both polymers, after the initial stage of their degradation mechanisms. The hydrocarbons formed are of variable structure, depending on the PVC concentration, which has a decisive role in the rate of formation.

\subsubsection{FTIR analysis of evolved gas during pyrolysis of $1: 3$ EVA/PVC mixtures}

Fig. 11 is the Gram-Schmidt diagram obtained by analysis with a heating rate of $30{ }^{\circ} \mathrm{C} \mathrm{min}{ }^{-1}$.

Fig. 11 shows that the shoulder on the Gram-Schmidt curve at $t_{4}$ has increased with the PVC content.

Fig. 12 shows the FTIR spectra corresponding to the six time values identified on the Gram-Schmidt profile (Fig. 11).

The first characteristic peaks of acetic acid (Fig. 12A) form after $560.4 \mathrm{~s}$. The absorbance increases to a maximum at $t_{5}$ on

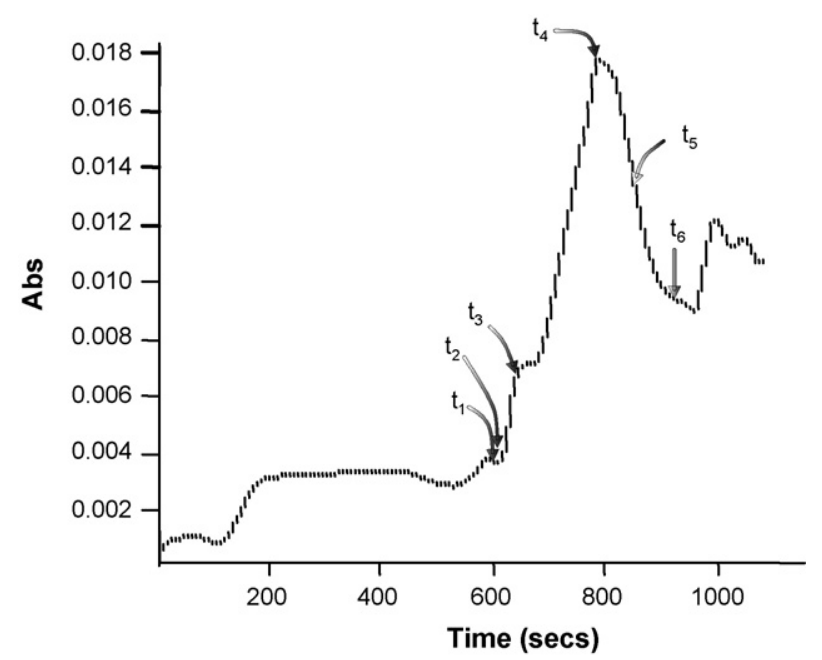

Fig. 9. Gram-Schmidt profile obtained by heating a 1:1 EVA-PVC mixture at $30{ }^{\circ} \mathrm{C} \min ^{-1}$. 

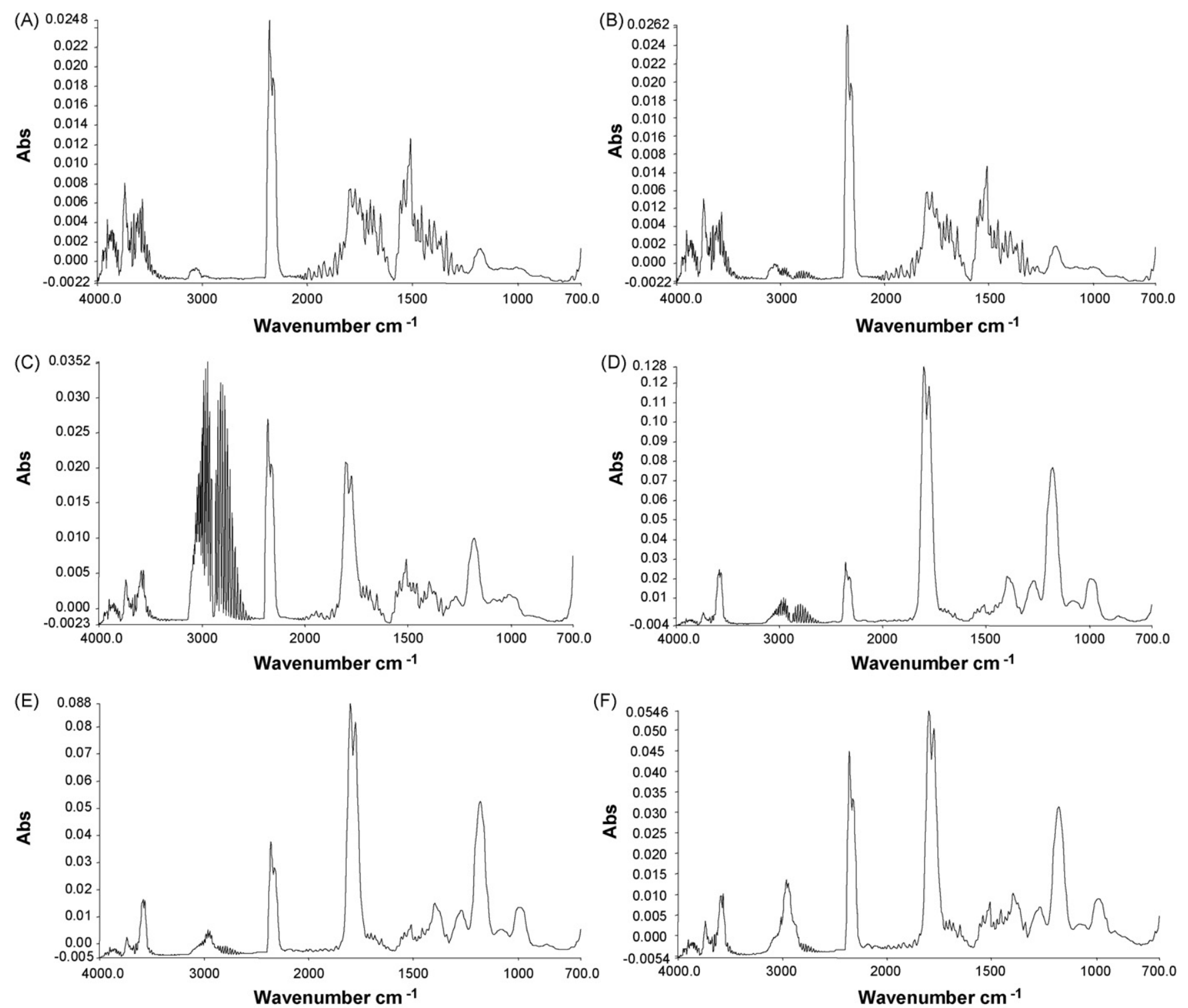

Fig. 10. IR absorption spectra recorded during degradation of the $1: 1 \mathrm{EVA} / \mathrm{PVC}$ mixture for different time values on the Gram-Schmidt profile: $(\mathrm{A}) t_{1}=604 \mathrm{~s}$, $T_{1}=357{ }^{\circ} \mathrm{C}$; (B) $t_{2}=609 \mathrm{~s}, T_{2}=359{ }^{\circ} \mathrm{C} ;(\mathrm{C}) t_{3}=643 \mathrm{~s}, T_{3}=377{ }^{\circ} \mathrm{C} ;(\mathrm{D}) t_{4}=790 \mathrm{~s}, T_{4}=450{ }^{\circ} \mathrm{C} ;(\mathrm{E}) t_{5}=856 \mathrm{~s}, T_{5}=483{ }^{\circ} \mathrm{C} ;(\mathrm{F}) t_{6}=920 \mathrm{~s}, T_{6}=519{ }^{\circ} \mathrm{C}$.

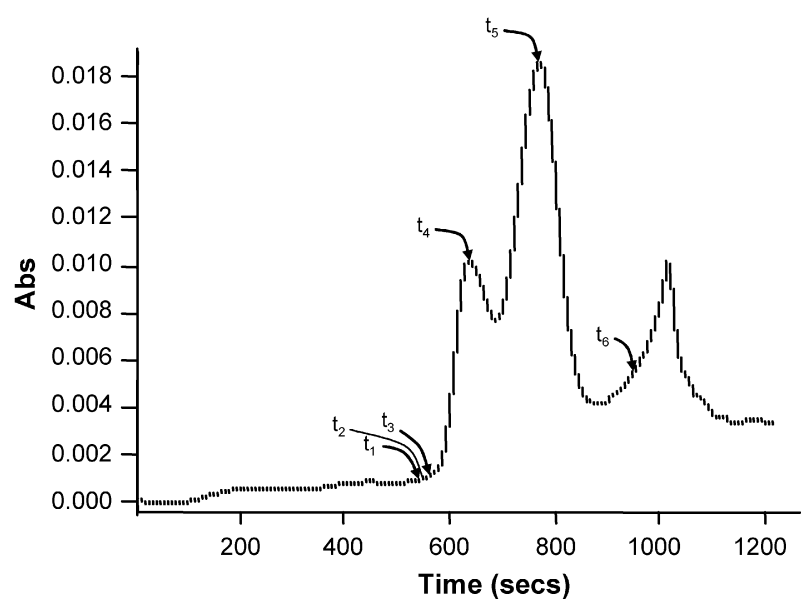

Fig. 11. Gram-Schmidt profile obtained by heating a 27/75 EVA-PVC mixture at $30{ }^{\circ} \mathrm{C} \min ^{-1}$. the Gram-Schmidt curve after $773.5 \mathrm{~s}$ (Fig. 12E). The absorbance diminishes after this point, then changes over time as the characteristic spectrum peaks of alkanes and then alkenes begin to form, while the $\mathrm{HCl}$ peaks begin to disappear and the intensity of the acetic acid peaks significantly diminishes. Fig. $12 \mathrm{~F}$ after $949 \mathrm{~s}$ shows the evolution of the alkane peak with the formation of a peak at $3018 \mathrm{~cm}^{-1}$ (alkene), the disappearance of $\mathrm{HCl}$, and strong deformation of the acetic acid peaks in the region between 1500 and $1000 \mathrm{~cm}^{-1}$.

Fig. 12B corresponds to the formation of the characteristic low-intensity $\mathrm{HCl}$ peaks between 3160 and $3000 \mathrm{~cm}^{-1}$. The acetic acid peaks begins to increase in intensity. The characteristic peaks of $\mathrm{HCl}$ gas appear immediately after the formation of acetic acid evolved by EVA degradation, which delays the formation of $\mathrm{HCl}$. Fig. 11A-D, i.e. four FTIR spectra recorded within just over $1 \mathrm{~min}$, show the high rate of $\mathrm{HCl}$ production. The intensity of the $\mathrm{HCl}$ peaks increases very 

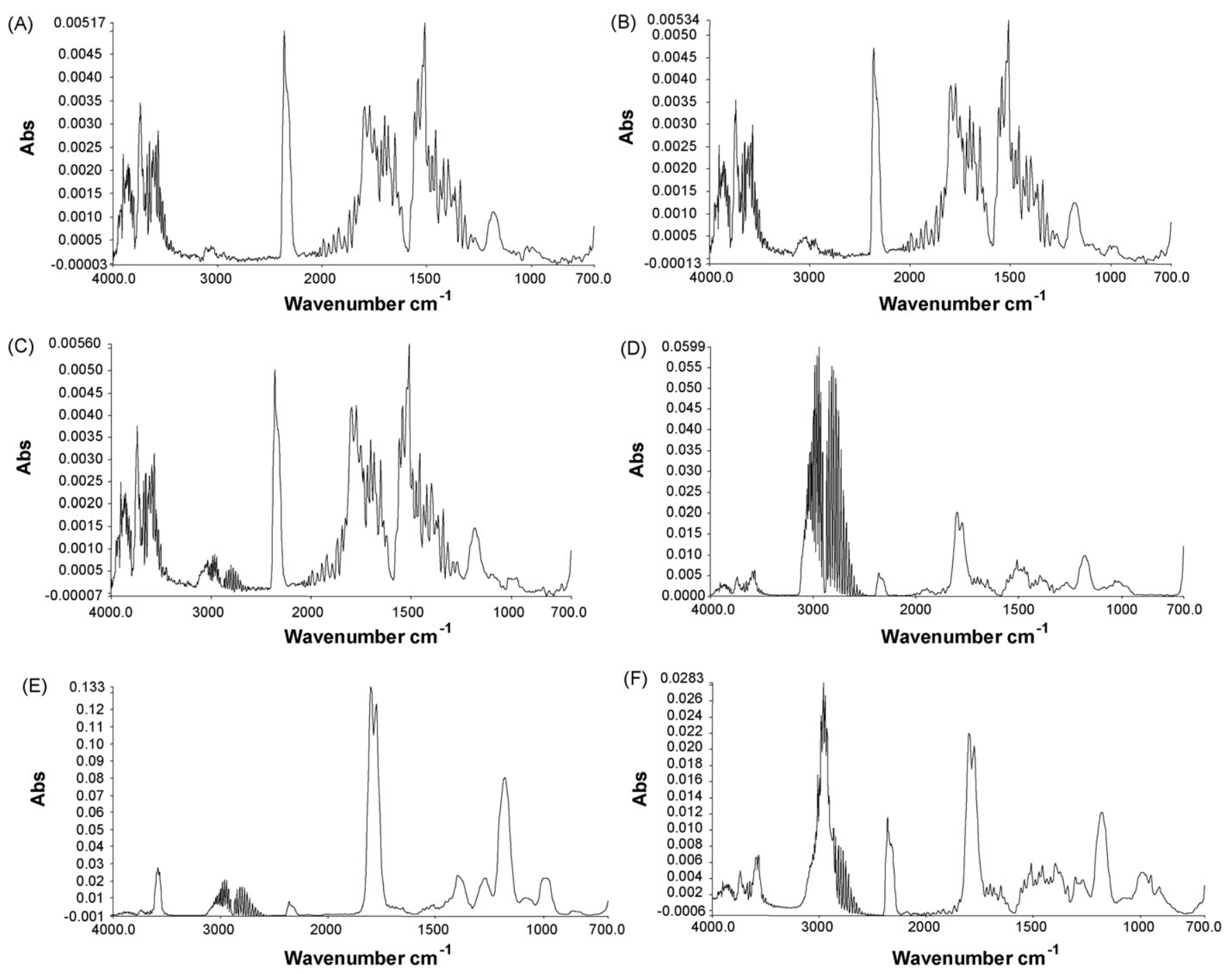

Fig. 12. IR absorption spectra recorded during degradation of the 1:3 EVA/PVC mixture for different time values on the Gram-Schmidt profile: (A) $t_{1}=560 \mathrm{~s}$, $T_{1}=335{ }^{\circ} \mathrm{C}$; (B) $t_{2}=565 \mathrm{~s}, T_{2}=337{ }^{\circ} \mathrm{C}$; (C) $t_{3}=569 \mathrm{~s}, T_{3}=340{ }^{\circ} \mathrm{C} ;(\mathrm{D}) t_{4}=638 \mathrm{~s}, T_{4}=374 ; \mathrm{E}: t_{5}=774 \mathrm{~s}, T_{5}=442{ }^{\circ} \mathrm{C} ;(\mathrm{F}) t_{6}=949 \mathrm{~s}, T_{6}=530{ }^{\circ} \mathrm{C}$.

quickly - faster with a PVC concentration of $75 \%$ than for the other mixtures - reaching a maximum after $637.8 \mathrm{~s}$ (Fig. 12D).

\subsection{FTIR analysis of evolved gas during thermal degradation of EVA/cellulose mixtures}

The most commonly accepted scheme for the pyrolytic degradation of cellulose postulates a single step during which several compounds are formed; the most important of these are water vapor, carbon dioxide $\mathrm{CO}_{2}$, carbon monoxide $\mathrm{CO}$, and hydrocarbon derivatives such as alkanes, alkenes, ketones, and aldehydes. These compounds can be identified from the characteristic peaks in Table 13 .

The ketones and aldehydes have a strong absorption band for the elongation of the $\mathrm{C}=\mathrm{O}$ group between 1870 and $1540 \mathrm{~cm}^{-1}$. Its relatively constant position, high intensity and independence with respect to interfering bands make it one of the easiest bands to recognize in IR spectra. Within its frequency range, the position of the $\mathrm{C}=\mathrm{O}$ elongation band is determined by the following factors: (1) the physical condition; (2) electronic and mass effects of neighboring substituents; (3) conjugation; (4) inter- and intramolecular hydrogen bridges; and (5) the ring tension. Allowing for these factors results in a substantial mass of data concerning the environment of the $\mathrm{C}=\mathrm{O}$ group. The aldehydes absorb at slightly higher frequencies than the methyl ketones. The aliphatic aldehydes absorb between 1740 and $1720 \mathrm{~cm}^{-1}$. The absorption of the aldehyde carbonyl group responds to structural variations in the same way as the ketones.

Table 13

Characteristic wave numbers of various compounds

\begin{tabular}{ll}
\hline Compound & Wave number $\left(\mathrm{cm}^{-1}\right)$ \\
\hline $\mathrm{CO}_{2}$ & $2400-2200$ \\
$\mathrm{CO}$ & $2200-2000$ \\
$\mathrm{H}_{2} \mathrm{O}$ & $3750-3500$ \\
$\mathrm{CnH}_{2 n+2}$ & $2800-3000$ \\
$\mathrm{CnH}_{2 n}$ & $3050-3150$ \\
Ketones & $1690-1750$ \\
Aldehydes & $1740-1800$ \\
\hline
\end{tabular}




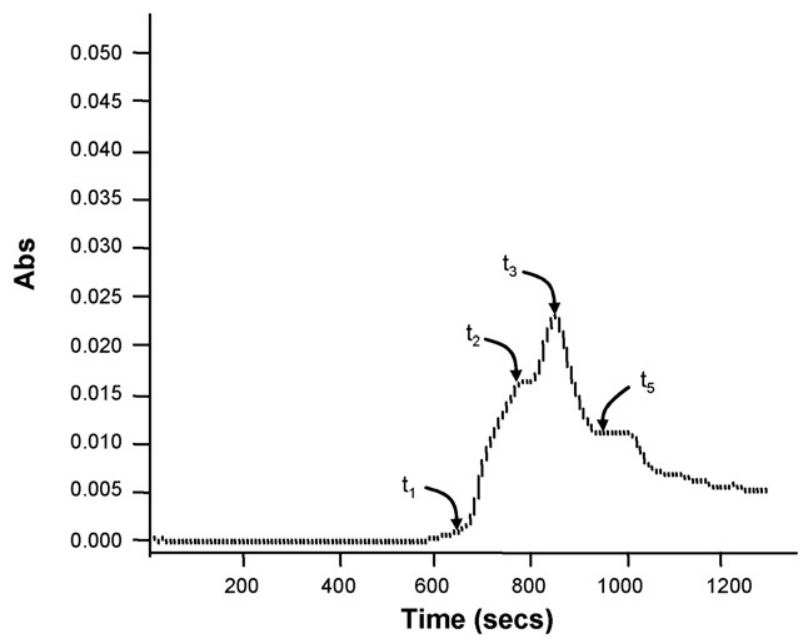

Fig. 13. Gram-Schmidt profile obtained by heating a 1:1 EVA-cellulose mixture at $30{ }^{\circ} \mathrm{C} \mathrm{min}^{-1}$.

Our objective was to identify the degradation chronology of the EVA-cellulose mixture while detecting possible effects interaction; we therefore began with a prior study [33] by identifying the characteristic spectra of the major gases evolved during the degradation of cellulose alone.

\subsubsection{FTIR analysis of evolved gas during pyrolysis of 1:1} EVA/cellulose mixtures

Unlike EVA-PVC mixtures, only a single 1:1 EVA/ cellulose mixture was used. Fig. 13 shows the Gram-Schmidt
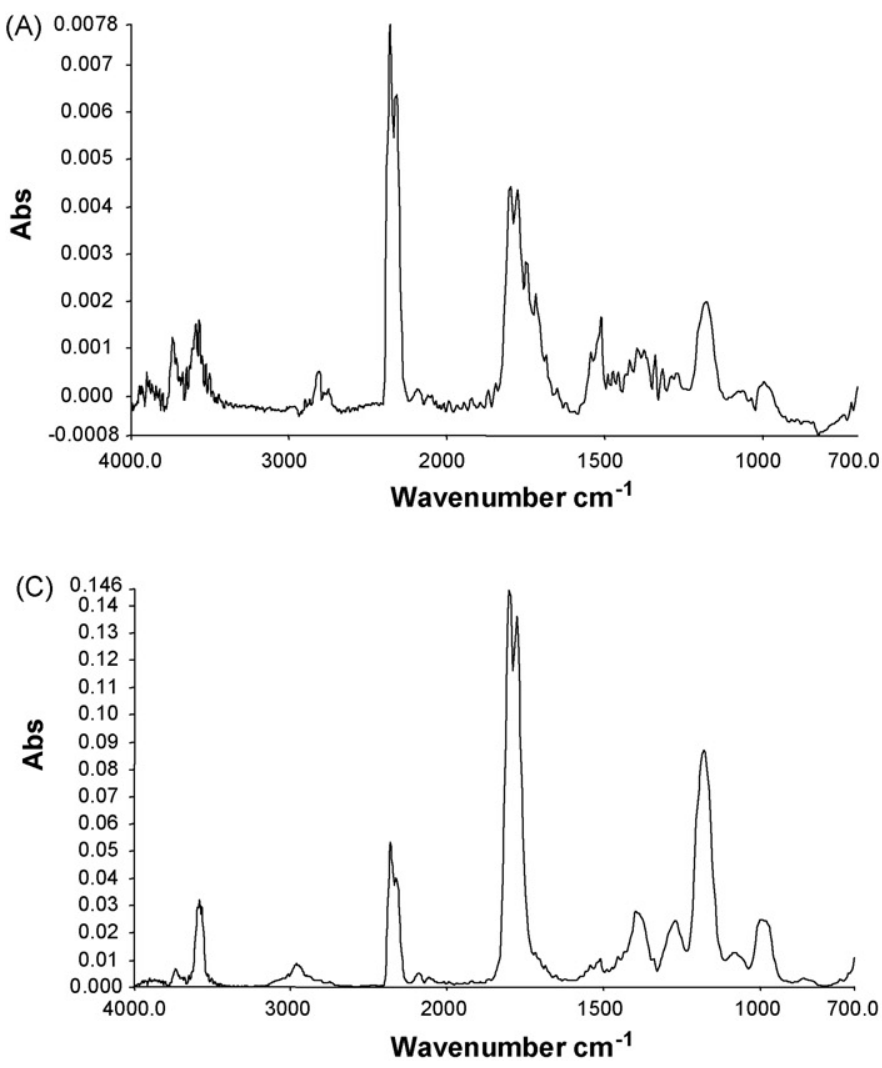

profile obtained for the mixture with a heating rate $30{ }^{\circ} \mathrm{C} \min ^{-1}$.

After the formation of the first compounds evolved during cellulose degradation, Fig. 14A shows the acetic acid peaks after 651.2 s, i.e. at $380.6{ }^{\circ} \mathrm{C}$. Fig. 14B illustrates the rapid evolution of the acetic acid peaks, the disappearance of water vapor, and a rise in the intensity of the $\mathrm{CO}$ and $\mathrm{CO}_{2}$ peaks to a maximum after $774.7 \mathrm{~s}$ (Fig. 14C) at $t_{3}$, i.e. the vertex of the Gram-Schmidt peak, which coincides here with the acetic acid peaks. Alkanes and alkenes begin to form beyond this point (peaks near $3000 \mathrm{~cm}^{-1}$ ) after 950.2 s. Fig. 14D (corresponding to $t_{4}$ on the Gram-Schmidt profile) reveals $\mathrm{CO}$ and $\mathrm{CO}_{2}$ as well as a small peak to the left of the acetic acid peak (wave number $3580.8 \mathrm{~cm}^{-1}$ ) and at $1500 \mathrm{~cm}^{-1}$, both of which are typical of cellulose degradation.

By comparison with the results obtained for the other EVA mixtures, there is a delay in the formation of the peaks for all the stages of EVA degradation. Moreover, the characteristic peaks of water vapor, $\mathrm{CO}_{2}$ and $\mathrm{CO}$ appear after $566.4 \mathrm{~s}$ $\left(338.2^{\circ} \mathrm{C}\right)$ for cellulose alone [33], whereas for the 1:1 EVAcellulose mixture the peaks for water vapor, $\mathrm{CO}_{2}$ and $\mathrm{CO}$ begin to form after $575.5 \mathrm{~s}\left(342.75^{\circ} \mathrm{C}\right)$. A delay is observed in the formation of the first cellulose degradation compounds when EVA is present. It is interesting at this point to review the results obtained by Matsuzawa, et al. [29] on the degradation of cellulose mixtures with other polymers (EVA was not tested by these authors). They observed a similar phenomenon only in mixtures with PVC. Unlike the other polymers tested, both
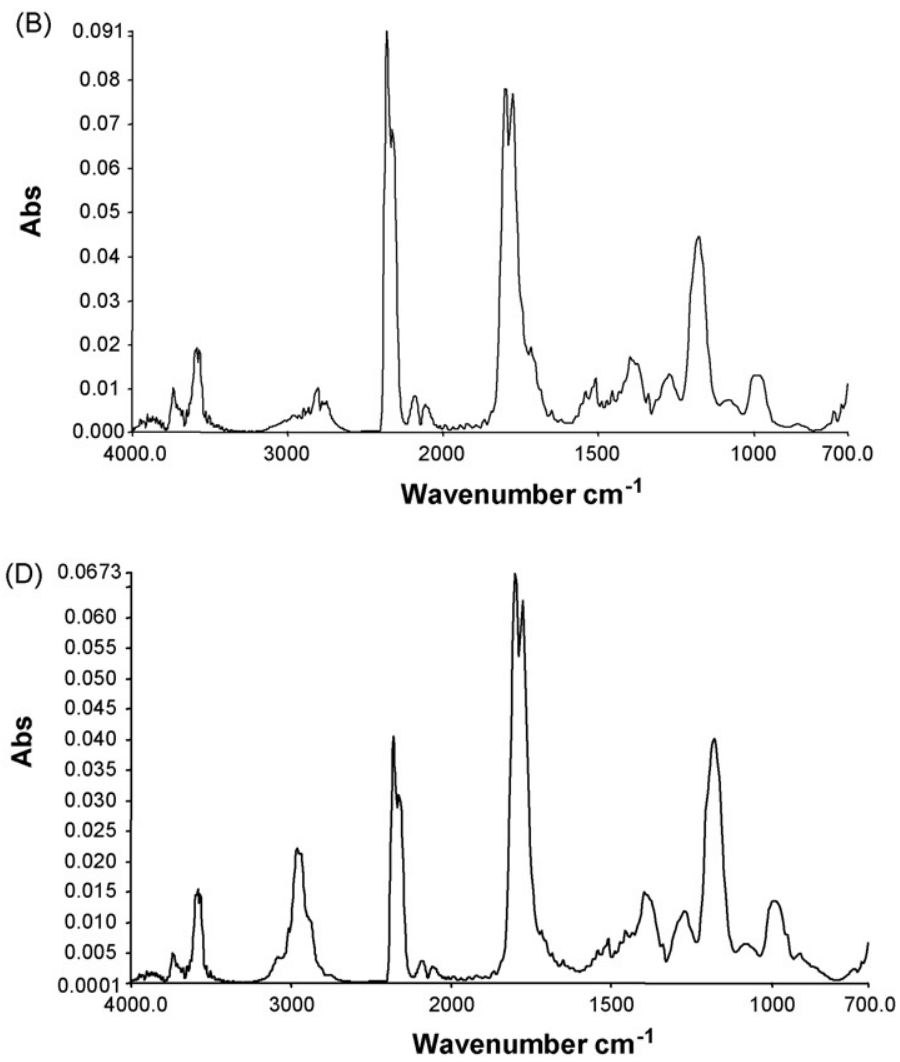

Fig. 14. IR absorption spectra recorded during degradation of the 1:1 EVA/cellulose mixture for different time values on the Gram-Schmidt profile: $(\mathrm{A}) t_{1}=651 \mathrm{~s}$, $T_{1}=381{ }^{\circ} \mathrm{C} ;(\mathrm{B}) t_{2}=775 \mathrm{~s}, T_{2}=519{ }^{\circ} \mathrm{C} ;(\mathrm{C}) t_{3}=852 \mathrm{~s}, T_{3}=481{ }^{\circ} \mathrm{C} ;(\mathrm{D}) t_{4}=950 \mathrm{~s}, T_{4}=607{ }^{\circ} \mathrm{C}$. 

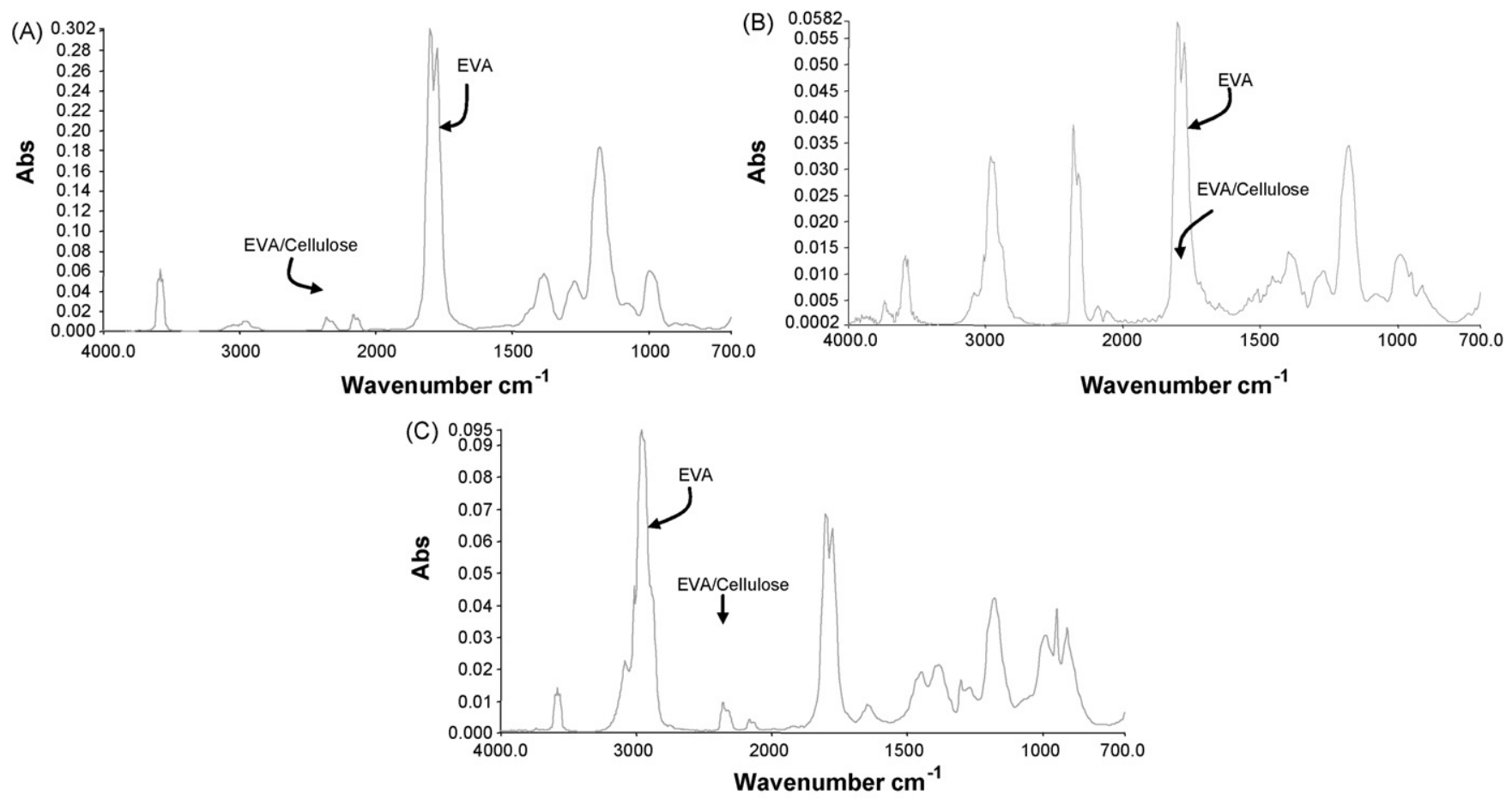

Fig. 15. Evolved gas spectra for thermal degradation of EVA (solid line) and a 1:1 EVA-cellulose mixture (broken line).

PVC and EVA form an acid during the first stage of degradation; in both cases, cellulose decomposes first, forming mainly $\mathrm{CO}_{2}, \mathrm{CO}$ and water vapor.

\subsubsection{Comparison of evolved gas spectra arising from the} degradation of cellulose, EVA, and a 1:1 EVA-cellulose mixture

Superimposing the spectra allowed us to identify the peaks in the mixed-polymer spectra from those of the individual polymers, and confirmed that cellulose is indeed degraded first.

Fig. 15 shows the superimposed spectra of the characteristic degradation peaks for EVA alone and for a 1:1 EVA-cellulose mixture at different moments during the degradation process.

Fig. 15A compares the spectrum at the beginning of the alkane formation stage for EVA alone (solid line) with the spectrum corresponding to the same stage of degradation of the 1:1 EVA-cellulose mixture (broken line). The total sample weight was comparable in both cases. The figure clearly shows the differences in the intensities of the characteristic peaks for acetic acid and the alkanes which, as expected, were roughly twice as intense for EVA alone as for the mixture. Other peaks that are not present in the degradation of pure EVA are visible in the mixture, e.g. the small peak at $1500 \mathrm{~cm}^{-1}$ and the one near the acetic acid peak at wave number $3580 \mathrm{~cm}^{-1}$ due to the presence of cellulose in the mixture. The intensity of the $\mathrm{CO}_{2}$ and CO peaks $\left(2600-2000 \mathrm{~cm}^{-1}\right)$ is higher in the mixture, once again due to the presence of cellulose.

Fig. 15B is a similar FTIR comparison, but after the formation of alkanes and alkenes. The intensities are different at this point, in particular for the $\mathrm{CO}_{2}$ and $\mathrm{CO}$ peaks. In addition, the $2000-4000 \mathrm{~cm}^{-1}$ region includes peaks in the
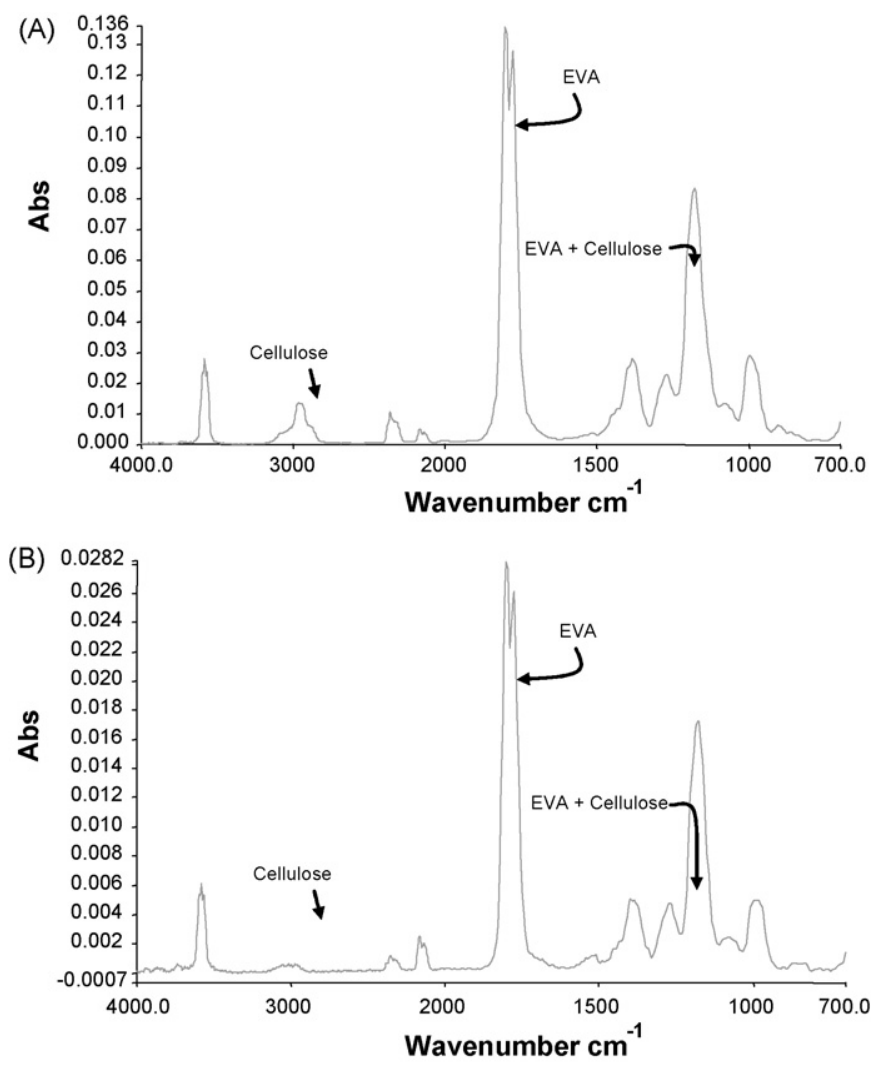

Fig. 16. Evolved gas spectra for thermal degradation of EVA (solid line), cellulose (fine dotted line), and a 1:1 EVA-cellulose mixture (bold broken line). 
mixed polymer spectrum that are not observed with EVA alone; the shape of the peaks in the region between 1500 and $1000 \mathrm{~cm}^{-1}$ is appreciably different due to the presence of cellulose.

Fig. $15 \mathrm{C}$ shows the same spectra at a more advanced stage of formation of the alkanes and alkenes. In the mixture the $\mathrm{CO}$ and $\mathrm{CO}_{2}$ peaks exhibit higher intensity than for EVA alone; the intensity of the alkane and alkene peaks is also much higher than for EVA alone.

Fig. 16 illustrates comparable results by superimposing the FTIR peaks recorded for EVA, cellulose, and the EVAcellulose mixture. The comparison in Fig. 16A clearly reveals the differences between the alkane-alkene peak obtained with EVA around $3000 \mathrm{~cm}^{-1}$ and the peak obtained with cellulose at $3000 \mathrm{~cm}^{-1}$ when the cellulose begins to degrade. The figure also shows that the peak near $1500 \mathrm{~cm}^{-1}$ and the peak at $3000 \mathrm{~cm}^{-1}$ typical of aldehyde carbonyl derivatives are characteristic of cellulose degradation. The intensity of the $\mathrm{CO}_{2}$ peak when cellulose is present may also be noted.

Fig. 16B shows that the formation of the aldehyde peak differs from that of the acetic acid peak at $1798-1776 \mathrm{~cm}^{-1}$. The peak at $1500 \mathrm{~cm}^{-1}$ is characteristic of cellulose degradation compounds.

\section{Conclusion}

The results of this investigation demonstrate the significant advantage of combining DTA, TGA, and FTIR for a better understanding of polymer degradation mechanisms. Four polymers were examined here: EVA, PS, PVC, and cellulose. Previous work [33] had identified the degradation sequence for each of the polymers individually, and one of the reasons for the present study was to determine whether mixed polymers are degraded without interactions.

Analysis of the results of pyrolysis monitored by thermogravimetry suggested an initial hypothesis concerning the chronological order of degradation of EVA/PS mixtures. Three weight losses were observed: EVA/PS/EVA* (the latter being an intermediate reaction compound); this led to the hypothesis of independent degradation of the polymers in the EVA/PS mixture. Thermogravimetry did not provide any conclusive results concerning chronological order of degradation for the EVA/PVC mixture, and independent degradation does not appear to be a valid hypothesis. These conclusions were confirmed by simulation in MATLAB and by comparing the theoretical and calculated mass values. Based on the degradation temperature ranges for the individual polymers, PVC should theoretically be degraded first, but FTIR analysis revealed that the first weight loss was due to EVA degradation. Interactions, therefore, occur between PVC and EVA within the mixture: hydrochloric acid evolved by pyrolysis of PVC catalyzes the degradation of EVA. The degradation mechanisms are more complex than in the simple hypothesis of independent reactions. The proposed degradation model hypothesis of independent behavior is therefore unsatisfactory. A strong interaction is observed within the mixture during thermal degradation.
The curves coincide for the EVA/PS mixture (0-10\% error); this is further confirmed by examining the order in which the reactants and intermediate reaction products disappear: EVA, PS, EVA*. The hypothetical independence of the degradation stages is thus confirmed for the EVA/PS mixture.

In the case of the EVA/cellulose mixture, the computer model curves do not coincide with the experimental curves. As for EVA/PVC mixture, the proposed independent reaction model is unsatisfactory. It appears likely that acetic acid affects cellulose degradation, and that interactions occur between the two compounds, although these interactions are less significant than for the EVA/PVC mixture. In this investigation using online analysis of the FTIR spectra of the evolved gas arising from pyrolytic degradation of EVA, PVC, and cellulose, we have demonstrated that the behavior of the polymers pyrolyzed individually differs from the behavior of the binary mixtures tested.

Our conclusions concerning the effect of the evolved acetic acid or $\mathrm{HCl}$ are supported by a recent publication [29] discussing the results of copolymerization experiments between cellulose and various polymers such as polyethylene, polystyrene, and PVC. Although the EVA/PVC mixture was not included in that study, the conclusions of those experiments corroborate the results of our own observations of mixed polymer behavior. According to the authors, cellulose is degraded independently in all the polymer mixtures studied except with PVC, notably in mixtures of cellulose and PS or, as in our study, EVA and PS. Conversely, cellulose interacted with PVC and degraded at a lower temperature than pure cellulose; the same behavior was observed in our study of the EVAcellulose mixture. Finally, cellulose in the mixture was degraded more than when it was pure; the difference is due to enhanced cellulose degradation, which could be attributable to acetic acid.

\section{References}

[1] M. Murata, T. Makino, Bull. Chem. Soc. Jpn. 6 (1979) 774.

[2] R. Knuemann, H. Bockhorn, Combust. Sci. Technol. (1994) 101-285.

[3] D. Munteanu, S. Turcu, Mater. Plastice 14 (3) (1977).

[4] N.S. Allen, M. Edge, M. Rodriguez, C.M. Liauw, E. Fontan, Polym. Degrad. Stab. 68 (2000).

[5] N.S. Allen, M. Edge, M. Rodriguez, C.M. Liauw, E. Fontan, Polym. Degrad. Stab. 71 (2000).

[6] D. Munteanu, S. Turcu, J. Thermal Anal. 20 (1981) 281.

[7] S.K. Dutta, A.K. Bhowmick, P.G. Mukunda, T.K. Chaki, Polym. Degrad. Stab. 50 (1995) 75-82.

[8] M. Shimoyama, H. Maeda, K. Matsukawa, H. Inoue, T. Ninomiya, Y. Ozaki, Vib. Spectrosc. (1997).

[9] K.R. Williams, J. Chem. Edu. (1994).

[10] Z. Wenwei, Z. Xiaoguang, Y. Li, Z. Yuefang, S. Jiazhen, Polymer 35 (15) (1994).

[11] M.B. Maurin, L.W. Dittert, A.A. Hussain, Thermochim. Acta 186 (1991) 97-102.

[12] M.B. Maurin, J.W.C. Pang, M.A. Hussain, Thermochim. Acta (1992).

[13] B.J. McGrattan, Soc. Appl. Spectrosc. 48 (12) (1994).

[14] L.M. Cunha, F.A.R. Oliveira, J. Food Eng. (2000).

[15] I.C. McNeill, Comprehensive Polymer Science, vol. 6, Pergamon Press, 1989;

G. Camino, R.Z. Sgobbi, S. Colombier, C. Scelza, Fire Matter 24 (2000) 85-90. 
[16] S.K. Dutta, A.K. Bhowmick, P.G. Mukunda, T.K. Chaki, Polym. Degrad. Stab. 50 (1995) 75-82.

[17] E.J. Moskala, D.W. Lee, Polym. Degrad. Stab. 25 (1989).

[18] D. Munteanu, S. Turcu, J. Thermal Anal. 20 (1981) 281.

[19] A. Marcilla, M. Beltran, Polym. Degrad. Stab. 50 (1995) 117-124.

[20] A. Marcilla, A. Gomez, J.A. Reyes, Polym. Degrad. Stab. (2001).

[21] U.K.O. Schröder, K.H. Ebert, A.W. Hamielec, Makromol. Chem. 185 (1984) 991.

[22] A. Marcilla, M. Beltran, Polym. Degrad. Stab. 48 (1995) 219-229.

[23] R. Knuemann, H. Bockhorn, Combust. Sci. Technol. 101 (1994) 285.

[24] C. Hssiung, C.Y. Chang, J.L. Hor, Waste Manage. 13 (1993) 221-235.

[25] H. Bockhorn, A. Hornung, U. Hornung, S. Teepe, J. Weichmann, Combust. Sci. Technol. 116-117 (1996) 129-151.

[26] G. Matuschek, N. Milanov, A. Kettrup, Thermochim. Acta 361 (2000) 7784.

[27] R. Miranda, J. Yang, C. Roy, C. Vasile, Polym. Degrad. Stab. 64 (1999) $127-144$.
[28] M. Mehl, A. Marongui, T. Favarelli, G. Bozzano, M. Dente, E. Ranzi, J. Anal. Appl. Pyrol. 72 (2004) 253-272.

[29] Y. Matsuzawa, M. Ayabe, J. Nishino, Polym. Degrad. Stab. 7 (2001) 435444.

[30] J.A. Conesa, J.A. Caballero, A. Marcilla, R. Font, Thermochim. Acta 254 (1995) 175-192.

[31] A.N. Garcia, A. Marcilla, R. Font, Thermochim. Acta 254 (1995) 277304.

[32] Khezami, Capart, 9th SFGP Conference, St Nazaire, France, 9-11 September, 2003.

[33] Y. Soudais, L. Moga, F. Lemort, J. Anal. Appl. Pyrol. (1931) 1-12.

[34] Fontana, A., La thermolyse au service du traitement des déchets: Actualité et perspectives. Université Libre de Bruxelles, Faculté des Sciences Appliquées, Faculté des Sciences Sociales, Politiques et Economiques, Ecole de Commerce Solvay, EFE-Paris, octobre 1998.

[35] A. Fontana, Ph. Laurent, C. Kestemont, C. Braekman-Danheux, Erdöl Erdgas Kohle 116 (2) (2000) 89-92. 